\title{
A new mechanistic framework to predict OCS fluxes from soils
}

\author{
Jérôme Ogée ${ }^{1}$, Joana Sauze ${ }^{1}$, Jürgen Kesselmeier ${ }^{2}$, Bernard Genty ${ }^{3}$, Heidi Van Diest ${ }^{2}$, Thomas Launois $^{1}$, and \\ Lisa Wingate ${ }^{1}$ \\ ${ }^{1}$ INRA, UMR 1391 ISPA, 33140 Villenave d'Ornon, France \\ ${ }^{2}$ Max Planck Institute for Chemistry, Biogeochemistry Department, Mainz, Germany \\ ${ }^{3}$ CNRS/CEA/Aix-Marseille University, UMR 6191 BVME, Saint-Paul-lez-Durance, France
}

Correspondence to: Jérôme Ogée (jerome.ogee@ bordeaux.inra.fr)

Received: 27 August 2015 - Published in Biogeosciences Discuss.: 22 September 2015

Revised: 15 March 2016 - Accepted: 21 March 2016 - Published: 18 April 2016

\begin{abstract}
Estimates of photosynthetic and respiratory fluxes at large scales are needed to improve our predictions of the current and future global $\mathrm{CO}_{2}$ cycle. Carbonyl sulfide (OCS) is the most abundant sulfur gas in the atmosphere and has been proposed as a new tracer of photosynthetic gross primary productivity (GPP), as the uptake of OCS from the atmosphere is dominated by the activity of carbonic anhydrase (CA), an enzyme abundant in leaves that also catalyses $\mathrm{CO}_{2}$ hydration during photosynthesis. However soils also exchange OCS with the atmosphere, which complicates the retrieval of GPP from atmospheric budgets. Indeed soils can take up large amounts of OCS from the atmosphere as soil microorganisms also contain CA, and OCS emissions from soils have been reported in agricultural fields or anoxic soils. To date no mechanistic framework exists to describe this exchange of OCS between soils and the atmosphere, but empirical results, once upscaled to the global scale, indicate that OCS consumption by soils dominates OCS emission and its contribution to the atmospheric budget is large, at about one third of the OCS uptake by vegetation, also with a large uncertainty. Here, we propose a new mechanistic model of the exchange of OCS between soils and the atmosphere that builds on our knowledge of soil $\mathrm{CA}$ activity from $\mathrm{CO}_{2}$ oxygen isotopes. In this model the OCS soil budget is described by a first-order reaction-diffusion-production equation, assuming that the hydrolysis of OCS by CA is total and irreversible. Using this model we are able to explain the observed presence of an optimum temperature for soil OCS uptake and show how this optimum can shift to cooler temperatures in the presence of soil OCS emission. Our model can also explain the observed optimum with soil moisture content previously described in the literature as a result of diffusional
\end{abstract}

constraints on OCS hydrolysis. These diffusional constraints are also responsible for the response of OCS uptake to soil weight and depth observed previously. In order to simulate the exact OCS uptake rates and patterns observed on several soils collected from a range of biomes, different $\mathrm{CA}$ activities had to be invoked in each soil type, coherent with expected physiological levels of CA in soil microbes and with CA activities derived from $\mathrm{CO}_{2}$ isotope exchange measurements, given the differences in affinity of CA for both trace gases. Our model can be used to help upscale laboratory measurements to the plot or the region. Several suggestions are given for future experiments in order to test the model further and allow a better constraint on the large-scale OCS fluxes from both oxic and anoxic soils.

\section{Introduction}

The terrestrial biosphere is, along with the ocean, the largest sink in the global atmospheric $\mathrm{CO}_{2}$ budget, with a very large year-to-year variability (e.g. Gurney and Eckels, 2011). Yet there is a scarcity of observations on how photosynthetic gross primary productivity (GPP) and respiration over land respond individually to warmer temperatures, increasing atmospheric $\mathrm{CO}_{2}$ mixing ratios and changes in water availability (Beer et al., 2010; Frankenberg et al., 2011; Welp et al., 2011; Wingate et al., 2009). Obtaining new observational constraints of these two opposing land $\mathrm{CO}_{2}$ gross fluxes at large scales is key to improving our models of the land $\mathrm{C}$ sink and providing robust projections of the atmospheric $\mathrm{CO}_{2}$ budget and future climate (Friedlingstein et al., 2006; Piao et al., 2013). 
In this context, additional tracers such as carbonyl sulfide (OCS), an analogue of $\mathrm{CO}_{2}$ in many respects, could be very useful (Berry et al., 2013; Campbell et al., 2008; Kettle et al., 2002; Montzka et al., 2007). Indeed, the uptake rate of OCS by foliage is strongly related to GPP (SandovalSoto et al., 2005; Stimler et al., 2010) or more generally to the rate of $\mathrm{CO}_{2}$ transfer into foliage (e.g. Seibt et al., 2010; Wohlfahrt et al., 2011). This is because both OCS and $\mathrm{CO}_{2}$ molecules diffuse into foliage through the same stomatal pores and through mesophyll cells, where they are rapidly hydrated in an enzymatic reaction with carbonic anhydrase (CA) (Protoschill-Krebs and Kesselmeier, 1992). However, unlike $\mathrm{CO}_{2}$, which is reversibly hydrated and converted into bicarbonate, OCS molecules are irreversibly hydrolysed (Elliott et al., 1989) and are not expected to diffuse back to the atmosphere, given the high affinity of CA towards OCS and the high activity of CA usually found in leaves (ProtoschillKrebs et al., 1996; Stimler et al., 2012).

Carbonic anhydrase is also widespread in diverse species from the Archaea, Bacteria, Fungi and Algae domains (Smith et al., 1999), so that OCS uptake can theoretically take place in soils. Several field studies provide support for this by showing that soils generally act as an OCS sink when measured at ambient concentrations (Castro and Galloway, 1991; Kuhn et al., 1999; J. Liu et al., 2010; Steinbacher et al., 2004; White et al., 2010; Yi et al., 2007) and that the uptake rate is reduced when the soil is autoclaved (Bremner and Banwart, 1976). Kesselmeier et al. (1999) also observed a significant (> 50\%) reduction of the OCS uptake rate in soil samples after adding ethoxyzolamide, one of the most efficient known CA inhibitors (e.g. Isik et al., 2009; Syrjänen et al., 2013). This finding strongly supports the idea that OCS uptake by soils is dominated by soil CA activity.

Soils can also emit OCS into the atmosphere as reported in some agricultural fields (Maseyk et al., 2014; Whelan and Rhew, 2015) or in anoxic soils (Devai and Delaune, 1995; Mello and Hines, 1994; Whelan et al., 2013; Yi et al., 2008) but the exact mechanisms for such emissions are still unclear (Mello and Hines, 1994; Whelan and Rhew, 2015). At the global scale, OCS consumption by soils seems to dominate OCS emission, and its contribution to the atmospheric budget is large, at about one third of the OCS uptake by vegetation, but with a large uncertainty (Berry et al., 2013; Kettle et al., 2002; Launois et al., 2015).

This large uncertainty in the OCS exchange rate from soils is partly caused by the variety of approaches used to obtain a global estimate of this flux. Kettle et al. (2002) assumed soil OCS fluxes responded to soil surface temperature and moisture only and used a parameterisation derived by Kesselmeier et al. (1999) from incubation measurements performed on a single agricultural soil in Germany. They recognised the limitation of such parameterisation and also noted the important role of some intrinsic properties of the soil and particularly its redox potential (Devai and Delaune, 1995), but did not account for it in their analysis. More recent approaches have assumed that the OCS flux from soils is proportional to other soil-air trace gas fluxes, such as heterotrophic (microbial) respiration (Berry et al., 2013) or the $\mathrm{H}_{2}$ deposition rate (Launois et al., 2015). Experimental evidence that supports such scaling between different trace gas fluxes, however, is scarce and with mixed results. In summary, all the approaches to estimating soil OCS fluxes at large scales remain essentially empirical or based on hypotheses that are largely unvalidated. Given the supposedly important contribution of soils in the global OCS atmospheric budget, it becomes apparent that a deeper understanding of this flux and its underlying mechanisms is urgently needed. Until then estimating global GPP using OCS as an additional tracer of the carbon cycle remains elusive.

A plethora of process-based models exist that describe the transport and fate of trace gases in porous media (Falta et al., 1989; Olesen et al., 2001). Transport processes are fairly well understood and similar between different trace gases. On the other hand the processes responsible for the emission or destruction are usually quite unique, i.e. specific to each trace gas. The main difficulty then resides in understanding these emission and destruction processes. Very recently Sun et al. (2015) proposed parameterisations of OCS emission and destruction in soils. However their parameterisations remain largely empirical and lack important drivers such as soil $\mathrm{pH}$ or redox potential. In this paper we propose a mechanistic framework to describe OCS uptake and release from soil surfaces, based on our current understanding of OCS biogeochemistry in soils. Our model includes OCS diffusion and advection through the soil matrix, OCS dissolution and hydrolysis in soil water and OCS production. Soil microbial activity contributes to OCS hydrolysis, through a pseudo firstorder CA-catalysed chemical reaction rate that varies with soil temperature and moisture, $\mathrm{pH}$ and $\mathrm{CA}$ concentration. OCS production, either abiotic or biotic, is also accounted for using a simple $\mathrm{Q}_{10}$-type temperature response modulated by the soil redox potential. Using the model we explore the theoretical response of OCS fluxes to soil water content, soil temperature, soil depth and soil $\mathrm{pH}$. We also evaluate our model against observed soil OCS uptake rates and patterns from the literature and discuss how the CA-catalysed reaction rates for each soil type can be reconciled with those typically observed for $\mathrm{CO}_{2}$ hydration, given the differences in affinity of CA for OCS and $\mathrm{CO}_{2}$.

\section{Model description}

\subsection{Partitioning of OCS in the different soil phases}

Carbonyl sulfide, like any other trace gas, can be present in the soil matrix in three forms: (1) vaporised in the airfilled pore space, (2) dissolved in the water-filled pore space or (3) adsorbed on the surface of the soil matrix (mineral and organic matter solid particles). The total OCS concentra- 
tion $C_{\mathrm{tot}}\left(\mathrm{mol} \mathrm{m}^{-3}\right.$ soil) is thus the sum of the OCS concentration in each phase weighted by their volumetric content: $C_{\text {tot }}=\varepsilon_{\mathrm{a}} C+\theta C_{1}+\rho_{\mathrm{b}} C_{\mathrm{s}}$ where $\varepsilon_{\mathrm{a}}\left(\mathrm{m}^{3}\right.$ air m ${ }^{-3}$ soil $)$ is the volumetric air content, $\theta\left(\mathrm{m}^{3}\right.$ water $\mathrm{m}^{-3}$ soil $)$ is the volumetric water content, $\rho_{\mathrm{b}}\left(\mathrm{kg} \mathrm{m}^{-3}\right)$ is soil bulk density, $C\left(\mathrm{~mol} \mathrm{~m}^{-3}\right.$ air) and $C_{1}\left(\mathrm{~mol} \mathrm{~m}^{-3}\right.$ water) denote OCS concentration in soil air and liquid water respectively and $C_{\mathrm{s}}\left(\mathrm{mol} \mathrm{kg}^{-1}\right.$ soil) denotes the OCS concentration adsorbed on the soil matrix.

In the following we will assume full equilibrium between the three phases. We will also assume linear sorption/desorption behaviour (a fair assumption at ambient OCS concentrations), so that $C_{1}$ and $C_{\mathrm{s}}$ can be linearly related to $C: C_{1}=B C$ where $B\left(\mathrm{~m}^{3}\right.$ water $\mathrm{m}^{-3}$ air $)$ is the solubility of OCS in water and $C_{\mathrm{s}}=\left(K_{\mathrm{sg}}+B K_{\mathrm{sw}}\right) C$ where $K_{\mathrm{sg}}\left(\mathrm{m}^{3}\right.$ air kg${ }^{-1}$ soil $)$ and $K_{\mathrm{sw}}\left(\mathrm{m}^{3}\right.$ water kg ${ }^{-1}$ soil $)$ are the solid/vapour and solid/liquid partitioning coefficients respectively (Olesen et al., 2001). The solubility $B$ is related to Henry's law constant $K_{\mathrm{H}}\left(\mathrm{mol} \mathrm{m}^{-3} \mathrm{~Pa}^{-1}\right): B=K_{\mathrm{H}} R T$ where $R=8.31446 \mathrm{~J} \mathrm{~mol}^{-1} \mathrm{~K}^{-1}$ is the ideal gas constant and $T(\mathrm{~K})$ is soil water temperature. It has been shown that $K_{\mathrm{H}}$ is fairly independent of $\mathrm{pH}$ (at least for $\mathrm{pH}$ below 9, see De Bruyn et al. (1995); Elliott et al., 1989) but decreased with temperature and salinity (De Bruyn et al., 1995; Elliott et al., 1989). In the following we will use the parameterisation of Wilhelm et al. (1977) assuming low salinity levels in the soil:

$K_{\mathrm{H}}=0.021 \exp [24900 / R(1 / T-1 / 298.15)]$.

We preferred this expression rather than the more recent expression proposed by De Bruyn et al. (1995) that was based on one single data set rather than a compilation of multiple data sets. The difference between the two expressions is shown in Fig. 1a.

Expressions of $K_{\mathrm{sg}}$ and $K_{\mathrm{sw}}$ for OCS are currently not available. For organic vapours it has been shown that $K_{\mathrm{sw}}$ is highly correlated with soil characteristics such as $\mathrm{C}$ content (Petersen et al., 1995), specific surface area or clay content (Yamaguchi et al., 1999), and that $K_{\text {sg }}$ is usually significant at soil water contents corresponding to less than five molecular layers of water coverage (Petersen et al., 1995). In this range of soil moisture, direct chemical adsorption onto dry mineral surfaces dominates and can increase the adsorption capacity of soils by several orders of magnitude. For these organic vapours the relationship of $K_{\text {sg }}$ with soil moisture can be related to soil specific surface area (Petersen et al., 1995) or clay content (Yamaguchi et al., 1999). However these relationships obtained for organic vapours are unlikely to be applicable for OCS because the adsorption mechanisms may be completely different. Liu and colleagues have estimated OCS adsorption capacities of several mineral oxides and found that quartz $\left(\mathrm{SiO}_{2}\right)$ and anatase $\left(\mathrm{TiO}_{2}\right)$ did not adsorb OCS but other oxides with higher basicity adsorbed, reversibly or not, rather large quantities of OCS (Liu et al., 2008, 2009, 2010a). They also recognised that these estimates of the adsorption capacity of the minerals were an upper limit owing to the competitive adsorption of other gases such as $\mathrm{CO}_{2}, \mathrm{H}_{2} \mathrm{O}$ and

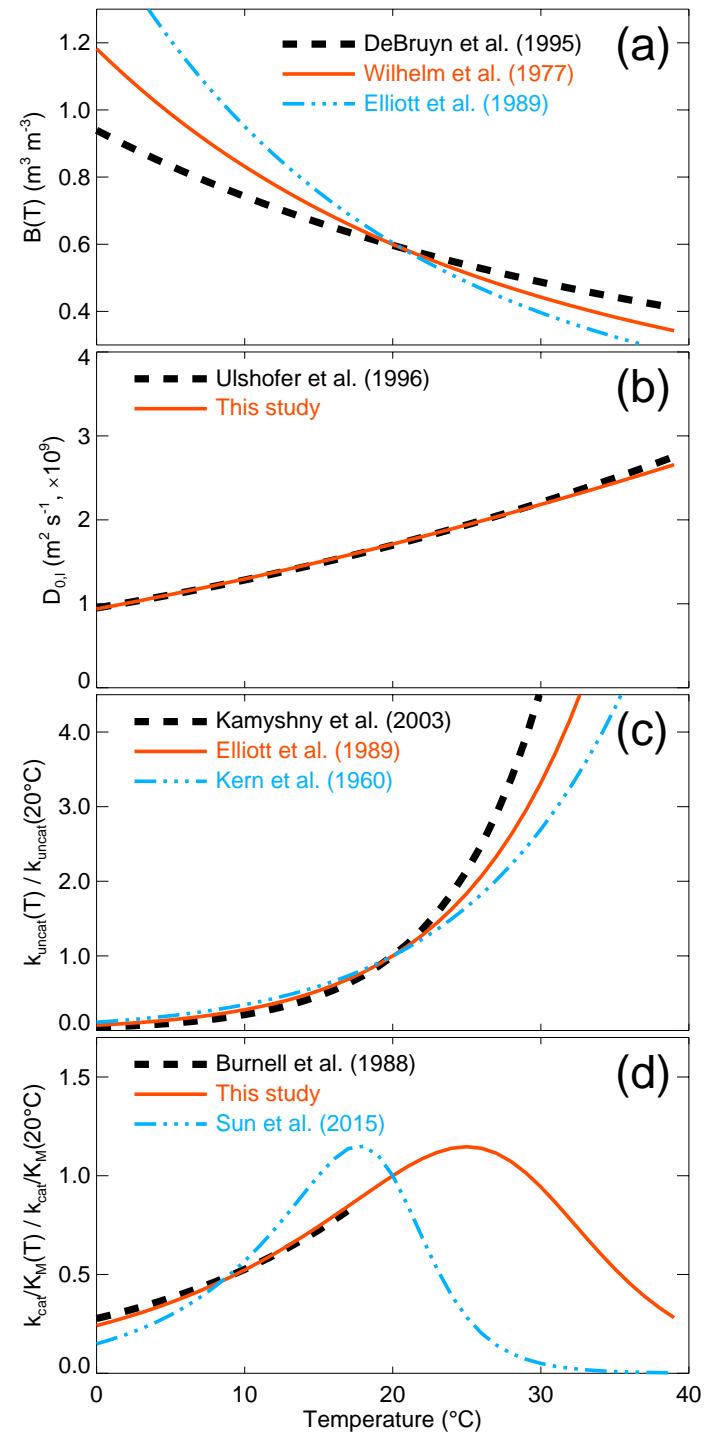

Figure 1. Temperature response of (a) the OCS solubility in water, (b) the OCS diffusivity in liquid water and (c) the uncatalysed and (d) CA-catalysed OCS hydrolysis rates. Red lines indicate the parameterisation used for this study.

$\mathrm{NO}_{x}$ that occur in the real Earth's atmosphere (Liu et al., 2009, 2010a) and the somewhat lower OCS partial pressure in ambient air compared to that used in their experimental setup. Also, at steady state, adsorption should have little influence on the soil-air OCS exchange rate, unless heterogeneous (surface) reactions occur and continuously remove OCS from the adsorbed phase (Liu et al., 2010a). In the following we will neglect adsorption of OCS on solid surfaces, but we recognise that this assumption might be an oversimplification. 


\subsection{Mass balance equation}

The transport of OCS through the soil matrix occurs by either pressure-driven (advective-dispersive) or concentrationdriven (diffusive) fluxes. Carbonyl sulfide can also be destroyed or emitted, owing to abiotic and/or biotic processes. The general mass balance equation for OCS in a small soil volume can then be written as follows:

$\frac{\partial \varepsilon_{\mathrm{tot}} C}{\partial t}=-\nabla F_{\mathrm{diff}}-\nabla F_{\mathrm{adv}}+P-S$,

where $\varepsilon_{\text {tot }}=\varepsilon_{\mathrm{a}}+\theta B+\rho_{\mathrm{b}} \quad\left(K_{\mathrm{sg}}+B K_{\mathrm{sw}}\right) \approx \varepsilon_{\mathrm{a}}+\theta B$ $\left(\mathrm{m}^{3}\right.$ air $\mathrm{m}^{-3}$ soil $)$ is total OCS soil porosity, $F_{\text {diff }}$ $\left(\mathrm{mol} \mathrm{m}{ }^{-2} \mathrm{~s}^{-1}\right)$ represents the diffusional flux of OCS through the soil matrix, $F_{\text {adv }}\left(\mathrm{mol} \mathrm{m}^{-2} \mathrm{~s}^{-1}\right)$ is the advective flux of OCS, $P\left(\mathrm{~mol} \mathrm{~m}^{-3} \mathrm{~s}^{-1}\right)$ the OCS production rate, $S\left(\mathrm{~mol} \mathrm{~m}^{-3} \mathrm{~s}^{-1}\right)$ the OCS consumption rate and $\nabla=\partial / \partial x+\partial / \partial y+\partial / \partial z$ denotes the differential operator, i.e. the spatial gradient in all three directions $x, y$ and $z$.

If the soil is horizontally homogeneous (that is, the soil properties are independent of $x$ and $y$ ) and the soil lateral dimensions are much larger than its total depth (minimal edge effects), the OCS concentration is only a function of soil depth $z$ and time $t$. Eq. (1) may be simplified:

$$
\frac{\partial \varepsilon_{\mathrm{tot}} C}{\partial t}=-\frac{\partial F_{\mathrm{diff}}}{\partial z}-\frac{\partial F_{\mathrm{adv}}}{\partial z}+P-S,
$$

\subsection{Diffusive fluxes}

Diffusion in the gas phase is commonly described by Fick's first law (Bird et al., 2002; Scanlon et al., 2002):

$F_{\text {diff,a }}=-D_{\text {eff,a }} \frac{\partial C}{\partial z}$,

where $F_{\text {diff,a }}\left(\mathrm{mol} \mathrm{m}^{-2} \mathrm{~s}^{-1}\right)$ is the diffusive flux of gaseous OCS and $D_{\text {eff,a }}\left(\mathrm{m}^{3}\right.$ air $\mathrm{m}^{-1}$ soil s$\left.{ }^{-1}\right)$ is the effective diffusivity of gaseous OCS through the soil matrix. The latter is commonly expressed relative to the binary diffusivity of OCS in free air $D_{0, \mathrm{a}}\left(\mathrm{m}^{2}\right.$ air s$\left.^{-1}\right): D_{\text {eff,a }} / D_{0, \mathrm{a}}=\tau_{\mathrm{a}} \varepsilon_{\mathrm{a}}$ where $\tau_{\mathrm{a}}$ is the so-called air tortuosity factor that accounts for the tortuosity of the air-filled pores, as well as their constrictivity and water-induced disconnectivity (e.g. Moldrup et al., 2003). The air-filled porosity $\left(\varepsilon_{\mathrm{a}}\right)$ appears in this equation to account for the reduced cross-sectional area in the soil matrix relative to free air, although the effective porosity for diffusion could be smaller if the soil contains small pores that do not contribute to the overall transport such as dead end or blind pores. Expressions for $\tau_{\mathrm{a}}$ differ depending on whether the soil is repacked or undisturbed (Moldrup et al., 2003). For undisturbed soils the most commonly used equations are those of Penman (1940); $\tau_{\mathrm{a}}=0.66$, hereafter referenced as Pen40, and Millington and Quirk (1961); $\tau_{\mathrm{a}}=\varepsilon_{\mathrm{a}}^{7 / 3} / \varphi^{2}$, where $\varphi$ is total soil porosity, hereafter referred to as MQ61. For repacked soils, equations proposed by
Moldrup et al. (2003); $\tau_{\mathrm{a}}=\varepsilon_{\mathrm{a}}^{3 / 2} / \varphi$, hereafter referred to as Mol03r are preferred. For undisturbed soils with high porosity such as volcanic ash, the expression proposed by Moldrup et al. $\left(2003 ; \tau_{\mathrm{a}}=\varepsilon_{\mathrm{a}}^{1+3 / b} / \varphi^{3 / b}\right.$, where $b$ is the pore-size distribution parameter) seems a better predictor (Moldrup et al., 2003). Recently a new density-corrected expression for undisturbed soils has also been proposed by Deepagoda et al. $\left((2011) ; \tau_{\mathrm{a}}=\left[0.2\left(\varepsilon_{\mathrm{a}} / \varphi\right)^{2}+0.004\right] / \varphi\right)$ that seems to be superior to previous formulations and has the advantage of not requiring knowledge of the pore-size distribution parameter $b$. A summary of these different formulations of the tortuosity factor and their range of application is given in Table 1.

Diffusion in the liquid phase is described in a similar fashion to the gas phase (Olesen et al., 2001):

$F_{\text {diff }, 1}=-D_{\text {eff }, 1} \frac{\partial C_{1}}{\partial z}=-D_{\text {eff }, 1}\left\{B \frac{\partial C}{\partial z}+C \frac{\mathrm{d} B}{\mathrm{~d} T} \frac{\partial T}{\partial z}\right\}$,

where $F_{\text {diff, } 1}\left(\mathrm{~mol} \mathrm{~m}^{-2} \mathrm{~s}^{-1}\right)$ is the diffusive flux of dissolved OCS in soil water and $D_{\text {eff, } 1}\left(\mathrm{~m}^{3}\right.$ water $\mathrm{m}^{-1}$ soil s$\left.{ }^{-1}\right)$ is the effective diffusivity of dissolved OCS through the soil matrix. As for gaseous diffusion $D_{\text {eff,1 }}$ is commonly expressed relative to the binary diffusivity of OCS in free water $D_{0,1}$ $\left(\mathrm{m}^{2}\right.$ water s$\left.^{-1}\right): D_{\text {eff, }, 1} / D_{0,1}=\tau_{1} \theta$ where $\tau_{1}$ is the tortuosity factor for solute diffusion. Different expressions for $\tau_{1}$ can also be found in the literature (Table 1).

Diffusion of OCS in the adsorbed phase can theoretically occur and can be described in a similar fashion to other trace gases (e.g. see Choi et al. (2001) for ozone). However we will neglect such a diffusion flux in the adsorbed phase because it is expected to be orders of magnitude smaller than in the two other phases. Also the binary diffusivity of any trace gas is several orders of magnitude higher in the air than it is for its dissolved counterpart in liquid water so that, in unsaturated (oxic) soils, $F_{\text {diff }}=F_{\text {diff,a }}+F_{\text {diff,1 }}$ is dominated by the gasphase OCS diffusion flux $F_{\text {diff,a }}$. The role of $F_{\text {diff, } 1}$ in the OCS transport equations becomes significant only when the soil is waterlogged.

The binary diffusivity $D_{0, \mathrm{a}}$ depends on pressure and temperature and is assumed here to follow the ChapmanEnskog theory for ideal gases (i.e. Bird et al., 2002): $D_{0, \mathrm{a}}(T, p)=D_{0, \mathrm{a}}\left(T_{0}, p_{0}\right)\left(T / T_{0}\right)^{1.5}\left(p_{0} / p\right)$. A value for $D_{0, \mathrm{a}}\left(25^{\circ} \mathrm{C}, 1 \mathrm{~atm}\right)$ of $1.27 \times 10^{-5} \mathrm{~m}^{2} \mathrm{~s}^{-1}$ is used and derived from the value for the diffusivity of water vapour in air at $25^{\circ} \mathrm{C}\left(2.54 \times 10^{-5} \mathrm{~m}^{2} \mathrm{~s}^{-1}\right.$, see Massman, 1998) and the $\mathrm{CO}_{2}$ / OCS diffusivity ratio of $2.0 \pm 0.2$ derived from the Chapman-Enskog theory and the difference in molar masses of OCS and $\mathrm{CO}_{2}$ (Seibt et al., 2010). The binary diffusivity $D_{0,1}$ also depends on temperature (Ulshöfer et al., 1996). Because the Stokes-Einstein equation only applies to spherical suspended particles, we preferred to use an empirical equation that works well for both the self-diffusivity of water and the diffusivity of dissolved $\mathrm{CO}_{2}$ in liquid water (Zeebe, 2011): $D_{0,1}(T)=D_{0,1}\left(T_{0}\right)\left(T / T_{0}-1\right)^{2}$, with $D_{0,1}$ $\left(25^{\circ} \mathrm{C}\right)=1.94 \times 10^{-9} \mathrm{~m}^{2} \mathrm{~s}^{-1}$ (Ulshöfer et al., 1996) and 
Table 1. Summary of tortuosity factor formulations for gaseous $\left(\tau_{\mathrm{a}}\right)$ and liquid $\left(\tau_{1}\right)$ diffusion from the literature. $\varepsilon_{\mathrm{a}}$ : air porosity; $\varphi$ : total porosity; $\theta$ : soil water content; $b$ : pore-size distribution parameter; NA: data not available.

\begin{tabular}{lllll}
\hline Notation & $\tau_{\mathrm{a}}$ & $\tau_{1}$ & Soil treatment & Reference \\
\hline Pen40 & 0.66 & 0.66 & NA & Penman (1940) \\
MQ61 & $\varepsilon_{\mathrm{a}}^{7 / 3} / \varphi^{2}$ & $\theta^{7 / 3} / \varphi^{2}$ & NA & Millington and Quirk (1961) \\
Mol03r & $\varepsilon_{\mathrm{a}}^{3 / 2} / \varphi$ & $\theta^{b / 3 / \varphi^{b / 3-1}}$ & repacked & Moldrup et al. (2003) \\
Mol03u & $\varepsilon_{\mathrm{a}}^{1+3 / b} / \varphi^{3 / b}$ & $\theta^{b / 3 / \varphi^{b / 3-1}}$ & undisturbed & Moldrup et al. (2003) \\
Deepa11 & {$\left[0.2\left(\varepsilon_{\mathrm{a}} / \varphi\right)^{2}+0.004\right] / \varphi$} & NA & undisturbed & Deepagoda et al. (2011) \\
\hline
\end{tabular}

$T_{0}=216 \mathrm{~K}$. This value of $T_{0}$ was chosen to be intermediate between the value used for water $(215.05 \mathrm{~K})$ and dissolved $\mathrm{CO}_{2}(217.2 \mathrm{~K})$ (Zeebe, 2011), and results in a temperature dependency of $D_{0,1}$ for OCS in water in very good agreement with relationships found in other studies (Fig. 1b).

\subsection{Advective fluxes}

Advection of OCS can occur in both the liquid and gas phases when the carrier fluid (water or air) moves relative to the soil matrix:

$F_{\mathrm{adv}, \mathrm{l}}=q_{1} C_{1}=q_{1} B C$,

$F_{\mathrm{adv}, \mathrm{a}}=q_{\mathrm{a}} C$,

where $q_{1}\left(\mathrm{~m} \mathrm{~s}^{-1}\right)$ and $q_{\mathrm{a}}\left(\mathrm{m} \mathrm{s}^{-1}\right)$ are the velocity fields for liquid water and air respectively. If the flow in the porous soil is laminar these velocity fields are given by Darcy's law (Massman et al., 1997; Scanlon et al., 2002):

$$
\begin{aligned}
& q_{1}=-\frac{k_{1}}{\mu_{1}} \frac{\partial \Psi_{1}}{\partial z}=-K_{1}\left(\frac{\partial h_{1}}{\partial z}+1\right), \\
& q_{\mathrm{a}}=-\frac{k_{\mathrm{a}}}{\mu_{\mathrm{a}}}\left(\frac{\partial p_{\mathrm{a}}}{\partial z}+\rho_{\mathrm{a}} g\right) .
\end{aligned}
$$

In Eqs. (6a) and (6b) $k_{1}$ and $k_{\mathrm{a}}\left(\mathrm{m}^{2}\right)$ denote soil permeabilities for liquid water and air respectively, $\mu_{1}$ and $\mu_{\mathrm{a}}$ $\left(\mathrm{kg} \mathrm{m}^{-1} \mathrm{~s}^{-1}\right)$ are water and air dynamic viscosities, $\Psi_{1}=$ $\rho_{1} g\left(h_{1}+z\right)$ is total soil water potential $(\mathrm{Pa}), \rho_{1}$ is water density $\left(1000 \mathrm{~kg} \mathrm{~m}^{-3}\right), h_{1}(\mathrm{~m})$ is matric potential height, $g$ is gravitational acceleration $\left(9.81 \mathrm{~m} \mathrm{~s}^{-2}\right), \rho_{\mathrm{a}}$ is air density (ca. $\left.1.2 \mathrm{~kg} \mathrm{~m}^{-3}\right)$ and $p_{\mathrm{a}}(\mathrm{Pa})$ is air pressure. We also defined the soil hydraulic conductivity $K_{1}\left(\mathrm{~m} \mathrm{~s}^{-1}\right): K_{1}=k_{1} \rho_{1} g / \mu_{1}$. In practice $p_{\mathrm{a}}$ can be expressed as the sum of the hydrostatic pressure $\left(p_{\mathrm{ah}}=-\rho_{\mathrm{a}} g z\right)$ and a fluctuating (non-hydrostatic) part: $p_{\mathrm{a}}=-\rho_{\mathrm{a}} g z+p_{\mathrm{a}}^{\prime}$ so that Eq. (6b) can be replaced by:

$q_{\mathrm{a}}=-\frac{k_{\mathrm{a}}}{\mu_{\mathrm{a}}} \frac{\partial p_{\mathrm{a}}^{\prime}}{\partial z}$.

From Eq. (6c) we can see that advection in the gas phase can result from pressure fluctuations, caused by, e.g. venting the soil surface (according to Bernouilli's equation) or turbulence above the soil surface. Typical air pressure fluctuations are of the order of $10 \mathrm{~Pa}$ (Maier et al., 2012; Massman et al., 1997). Pressure fluctuations can also result from nonhydrostatic density fluctuations caused by a change in the air composition with gas species of different molar mass as air or by temperature gradients, but the resulting flux is significant only in highly permeable (i.e. fractured) soils.

When averaged over a long enough timescale $(>1 \mathrm{~h})$ the advective flux starts to become negligible compared to the diffusive flux (e.g. Massman et al., 1997). Integration timescales of a few minutes were already assumed to allow liquid-vapour equilibration in Eq. (5a). In the following we will thus neglect advective fluxes in the OCS budget equation, keeping in mind that such an assumption is valid only for time scales of about $1 \mathrm{~h}$ or longer.

Even when advective fluxes are negligible, advection through porous media generates a diffusive-like flux called mechanical dispersion that reflects the fact that not everything in the porous medium travels at the average water or gas flow speed. Some paths are faster, some slower, some longer and some shorter, leading to a net spreading of the gas or solute plume that looks very much like diffusive behaviour. Since mechanical dispersion depends on the flow, it is expected to increase with increasing flow speed:

$$
\begin{aligned}
& F_{\text {disp }, 1}=-D_{\text {disp }, 1} \frac{\partial C_{1}}{\partial z}=-\alpha_{1}\left|q_{1}\right| \frac{\partial B C}{\partial z}, \\
& F_{\text {disp }, \mathrm{a}}=-D_{\text {disp }, \mathrm{a}} \frac{\partial C}{\partial z}=-\alpha_{\mathrm{a}}\left|q_{\mathrm{a}}\right| \frac{\partial C}{\partial z},
\end{aligned}
$$

where $\alpha_{1}(\mathrm{~m})$ and $\alpha_{\mathrm{a}}(\mathrm{m})$ are the longitudinal dynamic dispersivity of liquid water and air flow respectively and $D_{\text {disp,l }}$ $\left(\mathrm{m}^{2} \mathrm{~s}^{-1}\right)$ and $D_{\text {disp,a }}\left(\mathrm{m}^{2} \mathrm{~s}^{-1}\right)$ are the corresponding dispersive diffusivities. Transverse dispersion (i.e. in a plane perpendicular to the flow) can also occur but will be neglected here.

In practice, because of advective-dispersive fluxes, we must know the liquid water and air velocity fields $q_{1}$ and $q_{\mathrm{a}}$ in order to solve the trace gas OCS mass budget Eq. (2). This requires solving the total mass balance equations for liquid water and air separately. However, except during rain infiltration and immediate redistribution, $q_{1}$ rarely exceeds a few millimetres per day while the drift velocity, defined as the ratio $F_{\text {diff,a }} / C$, is typically of the order of a few millimetres per minute. For this reason, advection fluxes are generally neglected in soil gas transport models. Dispersive fluxes can 
still be accounted for as a correction factor to true diffusion, provided we have parameterisations of the dispersion diffusivities that are independent of the advective flux (e.g. expressions for $D_{\text {disp,a }}$ independent of $q_{\mathrm{a}}$ ). For example Maier et al. (2012) proposed expressions of $D_{\text {disp,a }} / D_{0, \text { a }}$ that rely on the air-filled porosity $\left(\varepsilon_{\mathrm{a}}\right)$ and permeability $\left(\mu_{\mathrm{a}}\right)$ of the soil and the degree of turbulence above the soil surface (characterised by the friction velocity $u_{*}$ ).

\subsection{Consumption and production rates}

The processes of consumption or production of OCS in a soil are not fully understood. Carbonyl sulfide can be consumed through hydrolysis in the bulk soil water at an uncatalysed rate $k_{\text {uncat }}\left(\mathrm{s}^{-1}\right)$ that depends mostly on temperature $T$ and $\mathrm{pH}$ (Elliott et al., 1989). In the following we will use the expression proposed by Elliott et al. (1989) because it covers the widest range of temperature and $\mathrm{pH}$ :

$$
\begin{aligned}
k_{\text {uncat }} & =2.15 \cdot 10^{-5} \exp \left(-10450\left(\frac{1}{T}-\frac{1}{298}\right)\right) \\
& +12.7 \cdot 10^{-\mathrm{pK}_{\mathrm{w}}+\mathrm{pH}} \exp \left(-6040\left(\frac{1}{T}-\frac{1}{298}\right)\right),
\end{aligned}
$$

where $\mathrm{pK}_{\mathrm{w}}$ is the dissociation constant of water. Other expressions are available in the literature and compared to Eq. (8) for both temperature (Fig. 1c) and pH (Fig. 2a) responses. Using Eq. (8) the uncatalysed OCS uptake rate is then computed as $S_{\text {uncat }}=k_{\text {uncat }} B \theta C$. The volumetric soil water content $\theta$ appears in this equation to convert the hydration rate from mol m${ }^{-3}$ water s ${ }^{-1}$ to $\mathrm{mol} \mathrm{m}^{-3}$ soil s$^{-1}$.

This uncatalysed rate is rather small and cannot explain the large OCS uptake rates observed in oxic soils (Kesselmeier et al., 1999; J. Liu et al., 2010; Van Diest and Kesselmeier, 2008). The main consumption of OCS is thought to be enzymatic and governed by soil microorganism CA activity (Kesselmeier et al., 1999; J. Liu et al., 2010; Van Diest and Kesselmeier, 2008). We will assume that such a catalysed reaction by CA-containing organisms can be described by Michaelis-Menten kinetics, as was observed for OCS in several marine algae species (Blezinger et al., 2000; ProtoschillKrebs et al., 1995) and one flour beetle (Haritos and Dojchinov, 2005). Because of the low concentrations of OCS in ambient air (500 ppt) and the comparatively high values of the Michaelis-Menten coefficient for OCS $\left(K_{\mathrm{m}}\right.$, see Ogawa et al. (2013); Protoschill-Krebs et al., 1995, 1996) the catalysed uptake rate $S_{\text {cat }}\left(\mathrm{mol} \mathrm{m}^{-3} \mathrm{~s}^{-1}\right)$ can be approximated:

$S_{\text {cat }}=\theta k_{\mathrm{cat}}[\mathrm{CA}] \frac{B C}{K_{\mathrm{m}}+B C} \approx \frac{k_{\mathrm{cat}}}{K_{\mathrm{m}}}[\mathrm{CA}] B \theta C$,

where $k_{\mathrm{cat}}\left(\mathrm{s}^{-1}\right)$ and $K_{\mathrm{m}}\left(\mathrm{mol} \mathrm{m}^{-3}\right)$ are the turnover rate and the Michaelis-Menten constant of the enzymatic reaction respectively and $[\mathrm{CA}]\left(\mathrm{mol} \mathrm{m}^{-3}\right)$ is the total CA concentration in soil water. We recognise that Eq. (9) is an oversimplification of the reality in the sense that $k_{\text {cat }}$ and $K_{\mathrm{m}}$ are not

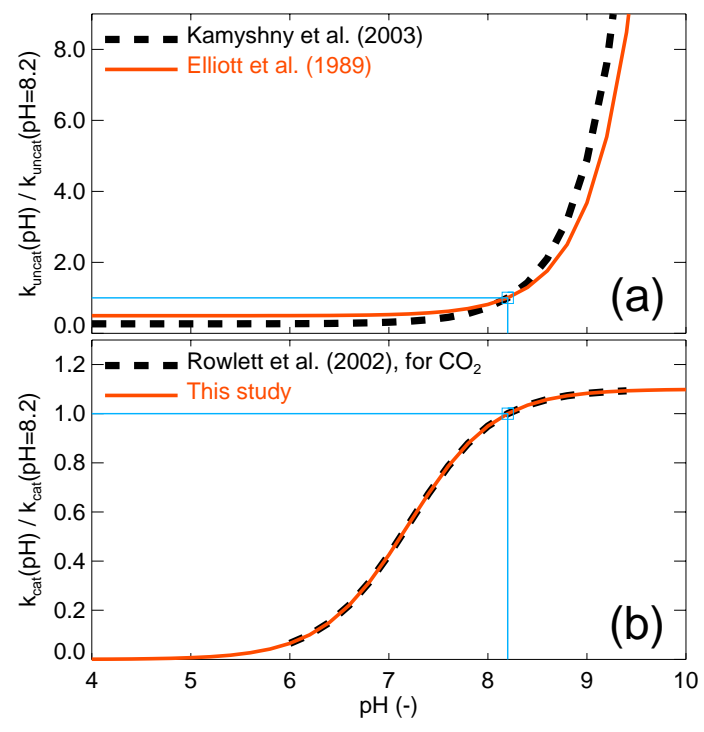

Figure 2. Response of the normalised (a) uncatalysed and (b) CAcatalysed OCS hydrolysis rates to changes in soil $\mathrm{pH}$. Red lines indicate the parameterisation used for this study. The blue lines indicate the normalisation at $\mathrm{pH}=8.2$.

true kinetic parameters but rather volume-averaged parameters for the entire soil microbial community. Also Eq. (9) neglects the competition for $\mathrm{CA}$ by $\mathrm{CO}_{2}$ molecules and the co-limitation of the uptake by diffusional constraints. Given the Michaelis-Menten constant of CA for $\mathrm{CO}_{2}\left(K_{\mathrm{m}, \mathrm{CO}_{2}}\right.$, of the order of $3 \mathrm{mM}$ at $25^{\circ} \mathrm{C}$ and $\left.\mathrm{pH} 8-9\right)$ and the range of $\mathrm{CO}_{2}$ mixing ratios encountered in soil surfaces $(300-5000 \mathrm{ppm}$ or $0.01-0.15 \mathrm{mM}$ at $25^{\circ} \mathrm{C}$ and $1 \mathrm{~atm}$ ), we can conclude that the competition with $\mathrm{CO}_{2}$ is negligible (i.e. the denominator in Eq. (9) would need to be multiplied by a factor $1+$ $\left[\mathrm{CO}_{2}\right] / K_{\mathrm{m}, \mathrm{CO}_{2}}$ which would deviate from unity by less than $5 \%$ ). We recognise that the $\mathrm{CO}_{2}$ concentration inside microbial cells (i.e. at the CA sites) must be somewhat larger than in the surrounding soil water but certainly not to an extent to justify accounting for competition between the two substrates. Also, using typical values of transfer conductance across cell wall and plasma membrane (Evans et al., 2009), we can show that the limitation of OCS uptake by diffusion into the microbial cells is negligible for calculating the OCS uptake rate (see Appendix A for a derivation). In the following we will therefore assume Eq. (9) to be valid.

As found for any enzymatic reaction, $k_{\text {cat }}$ and $K_{\mathrm{m}}$ depend on temperature and internal $\mathrm{pH}\left(\mathrm{pH}_{\mathrm{in}}\right)$. In the following we will assume that the ratio $k_{\mathrm{cat}} / K_{\mathrm{m}}$ has a temperature dependency that can be approximated:

$\frac{k_{\mathrm{cat}}}{K_{\mathrm{m}}} \propto x_{\mathrm{CA}}(T)=\frac{\exp \left(-\Delta H_{\mathrm{a}} / R T\right)}{1+\exp \left(-\Delta H_{\mathrm{d}} / R T+\Delta S_{\mathrm{d}} / R\right)}$,

where $\Delta H_{\mathrm{a}}, \Delta H_{\mathrm{d}}$ and $\Delta S_{\mathrm{d}}$ are thermodynamic parameters. In the following we will take $\Delta H_{\mathrm{a}}=40 \mathrm{~kJ} \mathrm{~mol}^{-1}$, $\Delta H_{\mathrm{d}}=200 \mathrm{~kJ} \mathrm{~mol}^{-1}$ and $\Delta S_{\mathrm{d}}=660 \mathrm{~J} \mathrm{~mol}^{-1} \mathrm{~K}^{-1}$, that leads 
to a temperature optima $T_{\mathrm{opt}, \mathrm{CA}}=25^{\circ} \mathrm{C}$ and reproduces well the temperature response of $\beta$-CA found on maize leaf extracts observed in the range $0-17^{\circ} \mathrm{C}$ by Burnell and Hatch (1988) (Fig. 1d). To our knowledge this is the only study that reports the temperature response of $\beta$-CA, the dominant CA class expected in soils (Smith et al., 1999). Interestingly our parameterisation of $x_{\mathrm{CA}}(T)$, based on direct measurements on $\beta$-CA from Burnell and Hatch (1988), is very different from the one used by Sun et al. (2015), especially at temperatures above $20^{\circ} \mathrm{C}$ (Fig. 1d).

The $\mathrm{pH}$ response of CA activity for OCS hydrolysis was described by a monotonically decreasing function towards more acidic $\mathrm{pH}_{\mathrm{in}}$, as observed in plant $\beta$-CA for both OCS (Protoschill-Krebs et al., 1996) and $\mathrm{CO}_{2}$ (Rowlett et al., 2002). In the following we will use the expression proposed by Rowlett et al. (2002) for $\mathrm{CO}_{2}$ :

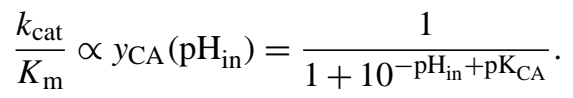

A value of $\mathrm{pK}_{\mathrm{CA}}=7.2$ was used that corresponds to the $\mathrm{CA}$ response of the wild-type Arabidopsis thaliana (Rowlett et al., 2002). The shape of the function $y_{\mathrm{CA}}$ is shown in Fig. $2 \mathrm{~b}$.

A $\beta$-CA $K_{\mathrm{M}}$ value for OCS $\left(39 \mu \mathrm{M}\right.$ at $20^{\circ} \mathrm{C}$ and $\left.\mathrm{pH} 8.2\right)$ was estimated on pea (Pisum sativum) by Protoschill-Krebs et al. (1996). From a reanalysis of the same data set we also estimated a $k_{\text {cat }}$ of $93 \mathrm{~s}^{-1}$ at the same temperature and $\mathrm{pH}$, leading to a $k_{\text {cat }} / K_{\mathrm{m}}$ value of $2.39 \mathrm{~s}^{-1} \mu \mathrm{M}^{-1}$. To our knowledge this is the only report of $k_{\text {cat }}$ and $K_{\mathrm{m}}$ values for OCS in $\beta$-CA.

The breaking of water film continuity that occurs at low soil water content leads to a reduction in microbial activity owing to the spatial separation of the microbes and their respiratory substrates (Manzoni and Katul, 2014). In our case soil water discontinuity should not affect OCS supply as gaseous OCS should be equally available in all soil pores. On the other hand different organisms may have different $k_{\text {cat }} / K_{\mathrm{m}}$ values so that the spatially-averaged $k_{\text {cat }} / K_{\mathrm{m}}$ could vary with drought-induced changes in microbial diversity. However our knowledge of how $k_{\text {cat }} / K_{\mathrm{m}}$ for OCS varies amongst different life forms is too scarce to know if it should increase or decrease during drought stress. We will therefore assume that soil water discontinuity does not affect $k_{\mathrm{cat}} / K_{\mathrm{m}}$ directly. CA concentration ([CA]) could also vary during drought stress, although it is not clear in which direction. During water stress, microbial activity such as respiration or growth is usually reduced, but slow growth rates and heat stress have been shown to cause an up-regulation of CA-gene expression in Escherichia coli (Merlin et al., 2003), probably because of a need of bicarbonate for lipid synthesis. For this study we thus make the simplifying assumption that CA concentration does not vary with soil water content. The catalysed OCS uptake rate $S_{\text {cat }}$ is then simply proportional to soil water content (Eq. 9).

Destruction of OCS can also occur in the solid phase and was observed on pure mineral oxides with high basicity (Liu et al., 2008, 2009, 2010a). However, such catalytic reaction should be significant only in very dry soils (with only a few molecular layers of water) and in the absence of other competitive adsorbents such as $\mathrm{CO}_{2}$ (Liu et al., 2008, 2010b) and is therefore neglected in our model. The total soil OCS uptake rate is thus computed as $S=k B \theta C$ :

$k=k_{\text {uncat }}(T, \mathrm{pH})+\frac{x_{\mathrm{CA}}(T)}{x_{\mathrm{CA}}\left(20^{\circ} \mathrm{C}\right)} \frac{y_{\mathrm{CA}}\left(\mathrm{pH}_{\mathrm{in}}\right)}{y_{\mathrm{CA}}(8.2)} 2390[\mathrm{CA}]$.

Following common practice in the $\mathrm{CO}_{2}$ literature, we will also express $k$ with respect to the uncatalysed rate at $25^{\circ} \mathrm{C}$ and $\mathrm{pH} 4.5$ :

$k=f_{\mathrm{CA}} k_{\text {uncat }}\left(25^{\circ} \mathrm{C}, \mathrm{pH}=4.5\right) x_{\mathrm{CA}}(T) / x_{\mathrm{CA}}\left(25^{\circ} \mathrm{C}\right)$,

where $f_{\mathrm{CA}}$ is the so-called soil CA enhancement factor. We can see from Eqs. (11a)-(b) that $f_{\mathrm{CA}}$ is not an intrinsic property of the soil and will vary with temperature and $\mathrm{pH}$, even at constant $\mathrm{CA}$ concentration. In the case where the catalysed rate dominates $k$ in Eq. (11a) and the internal pH is close to 8.2 we have: $f_{\mathrm{CA}} \approx 111[\mathrm{CA}$ ], where [CA] is in $\mathrm{nM}$.

In some situations the OCS uptake rates can be overridden by OCS production. This is the case when soil temperature rises above $25^{\circ} \mathrm{C}$ (Maseyk et al., 2014; Whelan and Rhew, 2015) or soil redox potential falls below $-100 \mathrm{mV}$ (Devai and Delaune, 1995). Light has also been proposed as an important trigger of OCS production, assuming photoproduction processes similar to those observed in ocean waters can occur (Whelan and Rhew, 2015). However the literature and data on this possible mechanism is still too scarce and not quantitative enough to be accounted for in our model.

The soil redox potential $\left(E_{h}\right)$ is a very dynamic variable that is not easily measured in the field, especially in unsaturated soils (e.g. van Bochove et al., 2002). Although $E_{h}$ and $\mathrm{pH}$ are linked, their relationship is not unique and depends on the set of oxidants and reductants present in the soil solution (e.g. Delaune and Reddy, 2005). Furthermore the soil redox potential is probably a more direct trigger for OCS production, as it defines when sulfate ions start to become limiting for the plants or the soil microbes (Husson, 2012). For this study we thus consider that, for anoxic soils at least, $E_{h}$ is the primary driver of OCS production, independently of $\mathrm{pH}$ :

$P=P_{\text {ref }} y_{\mathrm{P}}\left(E_{\mathrm{h}}\right) Q_{10}^{\left(T-T_{\mathrm{ref}}\right) / 10}$,

where $P_{\text {ref }}\left(\mathrm{mol} \mathrm{m}^{-3} \mathrm{~s}^{-1}\right)$ is the production rate at temperature $T_{\text {ref }}(\mathrm{K})$ and low $E_{h}$ (typically $-200 \mathrm{mV}$ ) and $Q_{10}$ is the multiplicative factor of the production rate for a $10^{\circ} \mathrm{C}$ temperature rise. Because soil OCS emission, when observed in oxic soils, usually occurs at temperature around $25^{\circ} \mathrm{C}$ or higher, we will set $T_{\text {ref }}$ as $25^{\circ} \mathrm{C}$ and thus $P_{\text {ref }}=P_{25}$. According to results from Devai and DeLaune (1995), the function $y_{\mathrm{P}}\left(E_{h}\right)$ may be expressed in the following manner:

$y_{\mathrm{P}}\left(E_{\mathrm{h}}\right)=\frac{1}{1+\exp \left(-\left(E_{\mathrm{h}}-100 \mathrm{mV}\right) / 20 \mathrm{mV}\right)}$, 
For oxic soils, Eq. (12a) would probably need to be modified to incorporate the effect of light on the OCS production rate (Whelan and Rhew, 2015) and the function $y_{\mathrm{P}}\left(E_{h}\right)$ given by Eq. (12b) may not hold. In any case it would be difficult to evaluate. Whether we should use UV light only or total solar radiation could also be debated. For all these reasons we decided in this study to only look at the effect of temperature on the OCS production rate and its consequences on the total OCS deposition rate.

\subsection{Steady-state solution}

The one-dimensional mass balance equation (Eq. 2) can be rewritten:

$$
\begin{aligned}
\frac{\partial \varepsilon_{\mathrm{t}} C}{\partial t} & =\frac{\partial}{\partial z}\left\{\left(D_{\text {eff, } \mathrm{a}}+\alpha_{\mathrm{a}}\left|q_{\mathrm{a}}\right|\right) \frac{\partial C}{\partial z}\right. \\
& \left.+\left(D_{\mathrm{eff}, 1}+\alpha_{1}\left|q_{1}\right|\right) \frac{\partial B C}{\partial z}\right\}+P-k B \theta C .
\end{aligned}
$$

Assuming steady-state conditions, isothermal and uniform soil moisture and porosity through the soil column, this simplifies to the following:

$D \frac{d^{2} C}{\mathrm{~d} z^{2}}-k B \theta C=-P$,

with:

$$
D=D_{\text {eff,a }}+\alpha_{\mathrm{a}}\left|q_{\mathrm{a}}\right|+\left(D_{\text {eff, }, 1}+\alpha_{1}\left|q_{1}\right|\right) B .
$$

Boundary conditions are $C(z=0)=C_{\mathrm{a}}$, the OCS concentration in the air above the soil column and $\mathrm{d} C / \mathrm{d} z\left(z=z_{\max }\right)=$ 0 , i.e. zero flux at the bottom of the soil column, located at depth $z_{\max }$ (the case for laboratory measurements). With such boundary conditions, the solution of Eq. (14) is the following:

$C(z)=z_{1}^{2} P+\left(C_{\mathrm{a}}-z_{1}^{2} P\right) \frac{e^{-z / z_{1}}+\xi^{2} e^{+z / z_{1}}}{1+\xi^{2}}$,

with $z_{1}^{2}=D / k B \theta$ and $\xi=e^{-z_{\max } / z_{1}}$. This leads to an OCS efflux at the soil surface:

$F=\sqrt{k B \theta D}\left(C_{\mathrm{a}}-\frac{z_{1}^{2} P}{D}\right) \frac{1-\xi^{2}}{1+\xi^{2}}$,

from which we can deduce the deposition velocity $V_{\mathrm{d}}=$ $-F / C_{\mathrm{a}}$.

For field data sets, the condition at the lower boundary should be modified to $\mathrm{d} C / \mathrm{d} z(z \rightarrow \infty)=0$ and the production rate $P$ should be positive and uniform only over a certain depth $z_{\mathrm{P}}$ below the surface. In this case the steady-state solution becomes the following:

$$
F=\sqrt{k B \theta D} \cdot\left(C_{\mathrm{a}}-\frac{z_{1}^{2} P}{D}\left(1-\exp \left(-z_{\mathrm{P}} / z_{1}\right)\right) .\right.
$$

We can verify that both equations give the same results if $z_{\max } \rightarrow \infty$ and $z_{\mathrm{P}} \rightarrow \infty$ and also that Eq. (17) leads to $F \rightarrow$ $-P \times z \mathrm{P}$ when $k \rightarrow 0$.

\subsection{Soil incubation data sets used for model validation}

The steady-state OCS deposition model presented here (Eq. 16) was evaluated against measurements performed on different soils in the laboratory. For this purpose we revisited the data set presented in Van Diest and Kesselmeier (2008). Volumetric soil moisture content $\left(\theta\right.$, in $\mathrm{m}^{3}\left(\mathrm{H}_{2} \mathrm{O}\right) \mathrm{m}^{-3}$ (soil)) was converted from gravimetric soil water content data $\left(M_{\mathrm{w}, \text { soil }}\right.$, in $\left.\mathrm{g}\left(\mathrm{H}_{2} \mathrm{O}\right) \mathrm{g}(\mathrm{soil})^{-1}\right)$ by means of the bulk density of the soil inside the chamber $\left(\rho_{\mathrm{b}}\right.$, in $\left.\mathrm{g} \mathrm{cm}^{-3}\right): \theta=$ $M_{\mathrm{w}, \text { soil }} \rho_{\mathrm{b}} / \rho_{\mathrm{w}}$, where $\rho_{\mathrm{w}}=1 \mathrm{~g} \mathrm{~cm}^{-3}$ is the density of liquid water. The soil bulk density was itself estimated from the maximum soil moisture content after saturation $\left(\theta_{\max }=\right.$ $\left.M_{\mathrm{w}, \text { soil,max }} \rho_{\mathrm{b}} / \rho_{\mathrm{w}}\right)$, assuming the latter corresponded to soil porosity $\left(\varphi=1-\rho_{\mathrm{b}} / 2.66\right)$, i.e. $\left(\rho_{\mathrm{b}}=1 /\left(M_{\mathrm{w}, \text { soil, max }} / \rho_{\mathrm{w}}+\right.\right.$ $1 / 2.66)$. Soil thickness $\left(z_{\max }\right)$ was further estimated using $\rho_{\mathrm{b}}$, soil dry weight ( $200 \mathrm{~g}$ for the German soil, $80 \mathrm{~g}$ for the other soils) and soil surface area $\left(165.1 \mathrm{~cm}^{2}\right)$ assuming soil density was uniform. Air porosity was calculated as $\varepsilon_{\mathrm{a}}=\varphi-\theta$. These estimates of $\theta, \varphi$ and $\varepsilon_{\mathrm{a}}$ were then used to compute $D$ (Eq. (15), assuming $\left|q_{\mathrm{a}}\right|=\left|q_{1}\right|=0$ ) and $F$ (Eq. (16b), with $P=0$ and $k$ estimated using Eq. (11b), with different $f_{\mathrm{CA}}$ values for each soil temperature incubation). Note that in these experiments, the air in the chamber headspace was stirred with fans above the soil surface so that dispersion fluxes may be large (i.e. $\left|q_{\mathrm{a}}\right|$ may not be zero). Without any more information about turbulence intensity at the soil surface in these experiments, we had to neglect this possible complication. We will discuss below how this simplification may affect the results of our simulations of these experiments.

\section{Results}

\subsection{Sensitivity to diffusivity model}

Given the large diversity of expressions for the air tortuosity factor $\left(\tau_{\mathrm{a}}\right)$ used to compute the effective diffusivity of OCS through the soil matrix, we felt it important to perform a sensitivity analysis of the model to different formulations available in the literature for $\tau_{\mathrm{a}}$. In Fig. 3 we show how the steady-state soil OCS deposition velocity model (Eq. 16b) responds to soil moisture or soil temperature for three different formulations of $\tau_{\mathrm{a}}$ : Pen40 $\left(\tau_{\mathrm{a}}=0.66\right), \operatorname{MQ61}\left(\tau_{\mathrm{a}}=\varepsilon_{\mathrm{a}}^{7 / 3} / \varphi^{2}\right)$ and $\operatorname{Mol} 03 \mathrm{r}\left(\tau_{\mathrm{a}}=\varepsilon_{\mathrm{a}}^{3 / 2} / \varphi\right)$. We also indicate the optimal soil moisture $\left(\theta_{\mathrm{opt}}\right)$ and temperature $\left(T_{\mathrm{opt}, V_{\mathrm{d}}}\right)$ for each formulation.

We found that the optimal temperature and the general shape of the response to temperature were not affected by the choice of the diffusivity model (Fig. 3, right panel). On the other hand the optimal soil moisture and the general shape of the response to soil moisture strongly depended on the choice made for $\tau_{\mathrm{a}}$ (Fig. 3, left panel). In particular the model of Penman (1940) gives a perfectly symmetric response to soil 


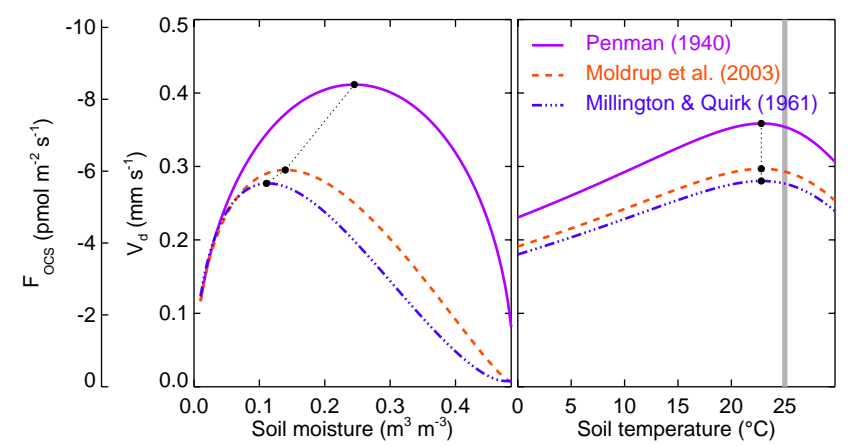

Figure 3. Sensitivity of the modelled OCS flux $\left(F_{\text {OCS }}\right)$ and deposition velocity $\left(V_{\mathrm{d}}\right)$ to the formulation used to describe gaseous and solute diffusion. The soil moisture and temperature response curves shown here were obtained assuming no source term, a soil depth and $\mathrm{pH}$ of $1 \mathrm{~m}$ and 7.2 respectively and a CA enhancement factor for OCS hydrolysis of 30000 . Closed circles indicate the temperature or soil moisture optimum of each response curve and the grey thick line in the right panel indicates the set optimal temperature for CA activity $\left(25^{\circ} \mathrm{C}\right.$ in this case $)$.

moisture with an optimal value at $\theta_{\mathrm{opt}}=0.50 \varphi$, unlike other formulations: $\theta_{\mathrm{opt}} \approx 0.23 \varphi$ for Millington and Quirk (1961) and $\theta_{\text {opt }} \approx 0.29 \varphi$ for Moldrup et al. (2003).

It is also noticeable on the right panel of Fig. 3 that the optimal temperature for $V_{\mathrm{d}}\left(T_{\mathrm{opt}, V_{\mathrm{d}}}\right)$ is actually lower than the prescribed optimal temperature for the catalysed OCS hydrolysis rate $\left(T_{\mathrm{opt}, \mathrm{CA}}=25^{\circ} \mathrm{C}\right.$ in this case $)$, even in the absence of an OCS source term. This is because $T_{\mathrm{opt}, V_{\mathrm{d}}}$ integrates other temperature responses from the total effective diffusivity $(D)$ and the OCS solubility $(B)$. Although these variables do not exhibit a temperature optimum, their temperature responses affect the overall value of $T_{\mathrm{opt}, V_{\mathrm{d}}}$. It can be shown analytically that this leads to $T_{\mathrm{opt}, V_{\mathrm{d}}}<T_{\mathrm{opt}, \mathrm{CA}}$.

\subsection{Sensitivity to soil depth}

Laboratory-based measurements of soil-air OCS fluxes are generally performed on small soil samples with a thickness of no more than a few centimetres. In contrast flux measurements performed in the field account for the entire soil column beneath the chamber enclosure. In order to see whether results from laboratory measurements could be directly applied to field conditions we performed a sensitivity analysis of the model to soil thickness (Fig. 4). We found that the responses to both soil moisture and soil temperature were affected by maximum soil depth $\left(z_{\max }\right)$, at least when $z_{\max }$ was below a few centimetres. Thin soils lead to lower maximum deposition rates but higher values of $\theta_{\mathrm{opt}}$ and $T_{\mathrm{opt}, V_{\mathrm{d}}}$. In Fig. 4 this is true mostly for $z_{\max }=1 \mathrm{~cm}$, and as soon as $z_{\max }$ reaches values above or equal to $3 \mathrm{~cm}$, the response curve becomes almost indistinguishable from that obtained with $z_{\max }=100 \mathrm{~cm}$.

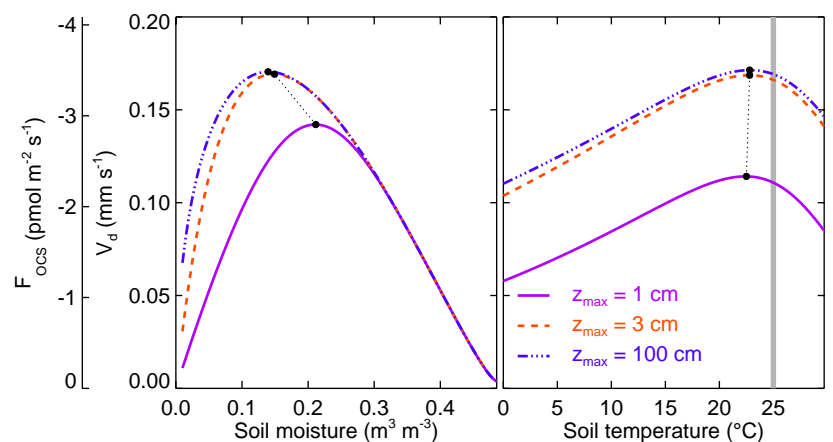

Figure 4. Sensitivity of the modelled OCS flux $\left(F_{\text {OCS }}\right)$ and deposition velocity $\left(V_{\mathrm{d}}\right)$ to soil column depth. The soil moisture and temperature response curves shown here were obtained using the diffusivity model of Moldrup et al. (2003) and assuming no source term, a soil $\mathrm{pH}$ of 7.2 and a CA enhancement factor for OCS hydrolysis of 10000 . Closed circles indicate the temperature or soil moisture optimum of each response curve and the grey thick line in the right panel indicates the set optimal temperature for CA activity $\left(25^{\circ} \mathrm{C}\right.$ in this case).

However this threshold on $z_{\max }$ also depends on soil CA activity. Results shown in Fig. 4 were obtained with an enhancement factor for OCS hydrolysis $f_{\mathrm{CA}}$ of only 10000 . An even smaller enhancement factor would have led to a deeper transition zone (e.g. about $10 \mathrm{~cm}$ with $f_{\mathrm{CA}}$ of 1000). This is because in Eq. (16b), the steady-state model of OCS deposition is proportional to tanh $\left(z_{\max } / z_{1}\right)$. Given the shape of the hyperbolic tangent function, we expect our steady-state OCS deposition velocity model to become insensitive to $z_{\max }$ as soon as $z_{\max } / z_{1} \geq 2$. With $z_{1}=\sqrt{D / k B \theta}$ and because $k$ is proportional to $f_{\mathrm{CA}}$ we can see that this condition on $z_{\max } / z_{1}$ will depend on $f_{\mathrm{CA}}$. At $f_{\mathrm{CA}}=1000$, we have $z_{1}\left(\theta_{\text {opt }}\right) \sim 5 \mathrm{~cm}$ while at $f_{\mathrm{CA}}=10000$ we have $z_{1}\left(\theta_{\mathrm{opt}}\right) \sim 1.5 \mathrm{~cm}$.

This response to soil depth was already observed by Kesselmeier et al. (1999), who reported measurements of OCS deposition velocity that increased linearly with the quantity of soil in their soil chamber enclosure up to $200 \mathrm{~g}$ of soil and then reached a plateau at around $400 \mathrm{~g}$. Because their soil samples were evenly spread inside the soil chamber, an increase in the quantity of soil directly translates into an increase in soil thickness. Using an enhancement factor $f_{\mathrm{CA}}$ of 27000 we were able to reproduce their saturation curve with soil weight using our steady-state model (Fig. 5). A lower $f_{\mathrm{CA}}$ value would have reduced the curvature of the model but would have also lowered the maximum $V_{\mathrm{d}}$ (not shown, but see Fig. 6). A value for $f_{\mathrm{CA}}$ of 27000 was the best compromise to match the observed saturation curve. Because different soil weights were measured at different times with new soil material each time, it is possible that they would correspond to slightly different $f_{\mathrm{CA}}$ values and this could explain the slight mismatch between the model and the fitted curve on the observations. 


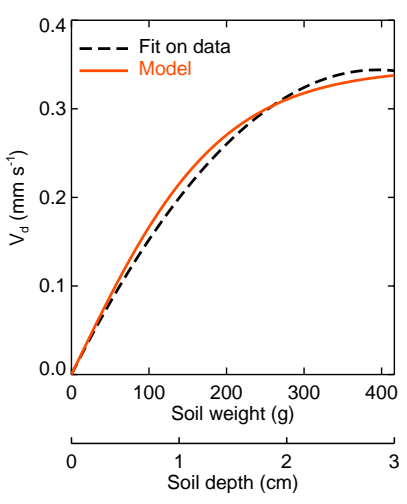

Figure 5. Modelled (solid line) and observed (dotted line) response of the modelled OCS deposition velocity $\left(V_{\mathrm{d}}\right)$ to soil column depth. Soil column depth is also converted into soil weight assuming a soil surface area of $165.1 \mathrm{~cm}^{2}$ and a soil bulk density and $\mathrm{pH}$ of $0.85 \mathrm{~kg} \mathrm{~m}^{3}$ and 7.2 respectively, to be comparable with the experimental setup used in Kesselmeier et al. (1999) to derive the observed response curve. Model results shown here were obtained using the diffusivity model of Moldrup et al. (2003) and assuming an enhancement factor and an optimum temperature for OCS hydrolysis of 26000 and $25^{\circ} \mathrm{C}$ respectively and no source term. Soil water content and temperature were also set to $11 \%$ weight and $17^{\circ} \mathrm{C}$ respectively, to be comparable with the experimental data, while the fit on observed uptake rates that was originally reported were converted into deposition velocities assuming a constant mixing ratio of 600 ppt (Kesselmeier et al., 1999).

\subsection{Sensitivity to soil CA activity and OCS emission rates}

Our model has two main parameters that need to be constrained by observations: these are the CA concentration (or conversely the CA enhancement factor $f_{\mathrm{CA}}$ ) and the OCS production rate at $25^{\circ} \mathrm{C}\left(P_{25}\right)$. A sensitivity analysis of our steady-state OCS deposition model to these two parameters is shown in Figs. 6 and 7. Both parameters affect the maximum deposition rates but in opposite directions, with high $f_{\text {CA }}$ values leading to higher $V_{\mathrm{d}}$ and high $P_{25}$ values leading to lower $V_{\mathrm{d}}$. This was expected from Eq. (16b) as $V_{\mathrm{d}}$ is proportional to $\sqrt{f_{\mathrm{CA}}}$ and is linearly and negatively related to $P_{25}$.

Interestingly, the optimal soil moisture is not modified by changes in $f_{\mathrm{CA}}$ (Fig. 6, left panel) and only slightly by $P_{25}$ (Fig. 7, left panel). This means that, provided that $z_{\max }$ is known precisely (or larger than $2 z_{1}$, see Sect. 3.2), the overall shape of the response to soil moisture (as typically measured during a drying cycle) and the exact value of $\theta_{\mathrm{opt}}$ are indicative solely of the diffusivity model to be used (Fig. 3). This result is important and should help us to at least decide whether the Pen 40 formulation for $\tau_{\mathrm{a}}$ must be used instead of a more asymmetrical one (the Mol03r and MQ61 formulations are harder to distinguish, see Fig. 3).

The value of $T_{\mathrm{opt}, V_{\mathrm{d}}}$ is also insensitive to changes in $f_{\mathrm{CA}}$ (Fig. 6, right panel), but diminishes when $P_{25}$ increases

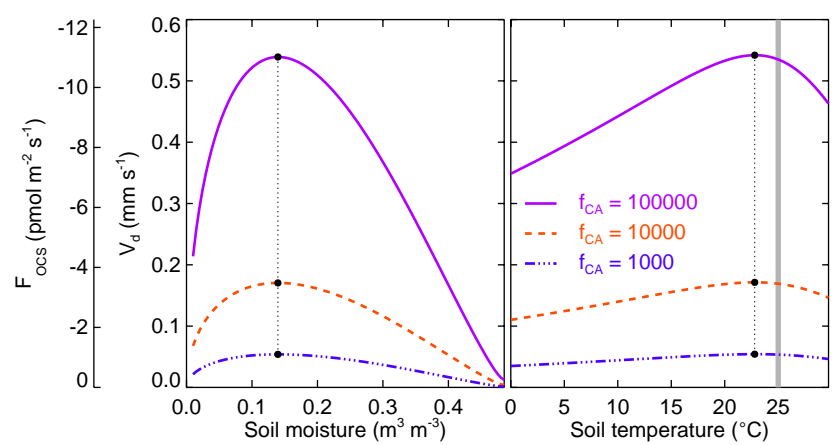

Figure 6. Sensitivity of the modelled OCS flux $\left(F_{\mathrm{OCS}}\right)$ and deposition velocity $\left(V_{\mathrm{d}}\right)$ to soil CA activity. The soil moisture and temperature response curves shown here were obtained using the diffusivity model of Moldrup et al. (2003) and assuming no source term, a soil $\mathrm{pH}$ of 7.2 and a soil depth of $1 \mathrm{~m}$. Closed circles indicate the temperature or soil moisture optimum of each response curve and the grey thick line in the right panel indicates the set optimal temperature for $\mathrm{CA}$ activity $\left(25^{\circ} \mathrm{C}\right.$ in this case).

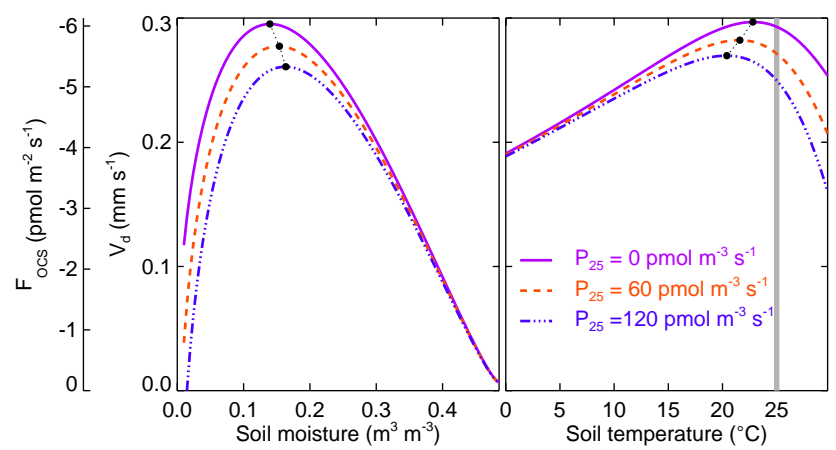

Figure 7. Sensitivity of the modelled OCS flux $\left(F_{\mathrm{OCS}}\right)$ and deposition velocity $\left(V_{\mathrm{d}}\right)$ to soil OCS emission rate. The soil moisture and temperature response curves shown here were obtained using the diffusivity model of Moldrup et al. (2003) and assuming a CA enhancement factor of 30000 , a soil $\mathrm{pH}$ of 7.2 and a soil depth of $1 \mathrm{~m}$. OCS source is assumed to occur only in the top $5 \mathrm{~cm}$. Closed circles indicate the temperature or soil moisture optimum of each response curve and the grey thick line in the right panel indicates the set optimal temperature for $\mathrm{CA}$ activity $\left(25^{\circ} \mathrm{C}\right.$ in this case).

(Fig. 7, right panel). This means that very low optimal temperature values $T_{\mathrm{opt}, V_{\mathrm{d}}}$ (i.e. unusually low compared to expected values for enzymatic activities and $T_{\mathrm{opt}, \mathrm{CA}}$ ) should be indicative of an OCS emission term, even if the values of $V_{\mathrm{d}}$ remain positive (i.e. the soil acts as a sink) in the temperature range explored. Of course at higher temperatures, and because in our model the OCS source term responds exponentially with temperature ( $Q_{10}$ response) while $k$ exhibits an optimal temperature $\left(T_{\mathrm{opt}, \mathrm{CA}}\right)$, the $V_{\mathrm{d}}$ should reach negative values if the value of $P_{25}$ is large and $f_{\mathrm{CA}}$ is low. In some extreme cases where $P_{25}$ fully dominates over $f_{\mathrm{CA}}$, our model could even predict OCS fluxes close to zero at temperatures below $\sim 10^{\circ} \mathrm{C}$ that would increase exponentially at warmer 


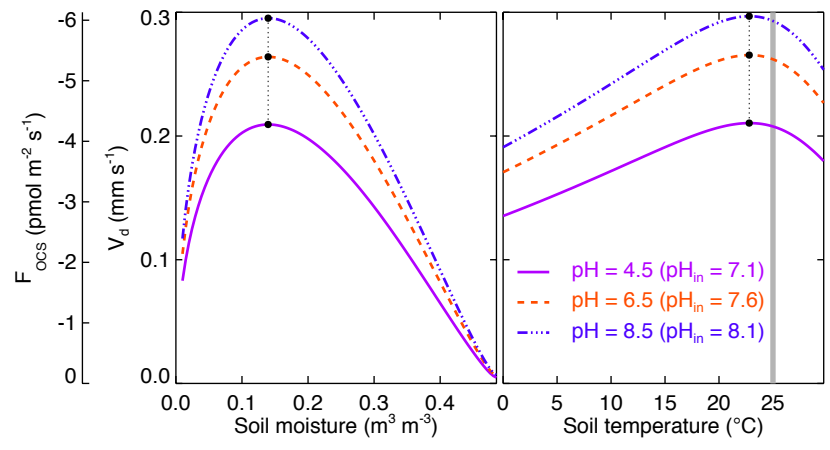

Figure 8. Sensitivity of the modelled OCS flux $\left(F_{\mathrm{OCS}}\right)$ and deposition velocity $\left(V_{\mathrm{d}}\right)$ to soil $\mathrm{pH}$. The soil moisture and temperature response curves shown here were obtained using the diffusivity model of Moldrup et al. (2003) and assuming no source term, a CA concentration in the soil of $330 \mathrm{nM}$ and a soil depth of $1 \mathrm{~m}$. Closed circles indicate the temperature or soil moisture optimum of each response curve and the grey thick line in the right panel indicates the set optimal temperature for $\mathrm{CA}$ activity $\left(25^{\circ} \mathrm{C}\right.$ in this case).

temperatures, as it has been observed in some agricultural soils (J. Liu et al., 2010; Maseyk et al., 2014; Whelan and Rhew, 2015).

\subsection{Sensitivity to soil $\mathrm{pH}$}

The sensitivity of our model to different soil $\mathrm{pH}$ was also tested. Because the effect of soil $\mathrm{pH}$ is mostly to modify the hydration rate $k$, we could not set a constant value of $f_{\mathrm{CA}}$. Instead we fixed the CA concentration in the soil $(330 \mathrm{nM})$ and also adjusted the internal $\mathrm{pH}$, assuming partial homeostasis with changes in soil $\mathrm{pH}$, as observed in bacteria (Krulwich et al., 2011): $\mathrm{pH}_{\text {in }}=6+0.25 \mathrm{pH}$ (Fig. 8). By assuming $\mathrm{pH}_{\text {in }}$ to vary with changes in soil $\mathrm{pH}$, we changed $k_{\text {cat }}($ Eq. 11a) and this was equivalent to changing $f_{\mathrm{CA}}$. Indeed results shown in Fig. 8 are very similar to those shown in Fig. 6 where low pH (and $\mathrm{pH}_{\text {in }}$ ) correspond to low $f_{\mathrm{CA}}$ values. If we had assumed that $\mathrm{pH}_{\text {in }}$ was not modified by soil $\mathrm{pH}$ (and fixed at 8.2) no change in $k_{\text {cat }}$ would have been observed and the change in $k$ would have only been caused by the effect of soil $\mathrm{pH}$ on $k_{\text {uncat }}$ (Eq. 11a). Unless the soil contains very little CA or the soil $\mathrm{pH}$ moves to very alkaline values (Fig. 2), this change in $k_{\text {uncat }}$ would have been too small to significantly affect $V_{\mathrm{d}}$. Indeed at a CA concentration of $330 \mathrm{nM}$ and with a $\mathrm{pH}_{\text {in }}$ maintained at 8.2, our model Eq. (16b) gives exactly the same values for soil $\mathrm{pH}$ ranging from 4 to 9 . In summary, within the range of soil $\mathrm{pH}$ found in nature, the response of $V_{\mathrm{d}}$ to this environmental factor is only happening through its influence on $\mathrm{pH}_{\text {in }}$ and hence on $k_{\text {cat }}$ (Eq. 10b and Fig. 2b).

\subsection{Model evaluation against lab-based drying curves}

Our steady-state OCS deposition model was further evaluated against experimental data from Van Diest and Kesselmeier (2008) and results are shown in Figs. 9-12 for different soils. Because OCS deposition values observed by Van Diest and Kesselmeier (2008) were all positive we set the source term to zero $\left(P_{25}=0\right)$, although we recognise that this may be an oversimplification. We also set the optimum temperature for the catalysed OCS hydration rate to $25^{\circ} \mathrm{C}$. A value for $f_{\mathrm{CA}}$ was then manually adjusted for each soil and each temperature, between 21600 and 336000 , depending on the soil origin and temperature (Figs. 9-12). Once this adjustment on $f_{\mathrm{CA}}$ was done, our model, with the diffusivity formulation of Moldrup et al. (2003), was able to reproduce most observed response curves to soil drying (Figs. 9-12, left and middle panels). The model was also able to reproduce, within the measurement uncertainties, the temperature dependency of $V_{\mathrm{d}}$ at a soil moisture level of $0.12 \mathrm{~m}^{3} \mathrm{~m}^{-3}$ (far right panels in Figs. 9-12).

\section{Discussion}

\subsection{Can the proposed model explain observations realistically?}

Many studies have clearly demonstrated that soil moisture strongly modulates OCS uptake by soils, with an optimal soil moisture content usually around $12 \%$ of soil weight (Kesselmeier et al., 1999; J. Liu et al., 2010; Van Diest and Kesselmeier, 2008). As noted in some of these studies, such a bell-shape response is indicative of reactional and diffusional limitations at low and high soil moisture contents respectively. Using our steady-state formulation for shallow soils (Eq. 16b) we were able to reproduce the soil moisture response observed experimentally (Figs. 9-12). We also found that the observed asymmetric response to soil moisture was best captured by the soil diffusivity model of Moldrup et al. (2003) or Millington and Quirk (1961) and showed that the optimum soil moisture could be related to soil porosity: $\theta_{\mathrm{opt}}=0.3 \varphi / 1.3$ for MQ61 and $\theta_{\mathrm{opt}}=2 \varphi / 7$ for Mol03r. Using our model we were also able to explain the response of OCS uptake to soil weight (i.e. soil thickness) observed by Kesselmeier et al. (1999) (Fig. 5).

We also tested our model against observations of the temperature response of $V_{\mathrm{d}}$. Empirical studies showed that, for a given soil, the maximum OCS uptake rate was modulated by incubation temperature, with an optimal temperature ranging from 15 to $35^{\circ} \mathrm{C}$ (Kesselmeier et al., 1999; J. Liu et al., 2010; Van Diest and Kesselmeier, 2008). This temperature response was interpreted as an enzymatically catalysed process, governed by soil microorganism CA activity (Kesselmeier et al., 1999; J. Liu et al., 2010; Van Diest and Kesselmeier, 2008). To reproduce this response of $V_{\mathrm{d}}$ to incubation temperature using our steady-state model, we had to manually adjust $f_{\mathrm{CA}}$ for each incubation temperature. We will argue here that using different $f_{\mathrm{CA}}$ values on the same soil is justified given the way measurements were performed. Van Diest and Kesselmeier (2008) wanted to characterise 


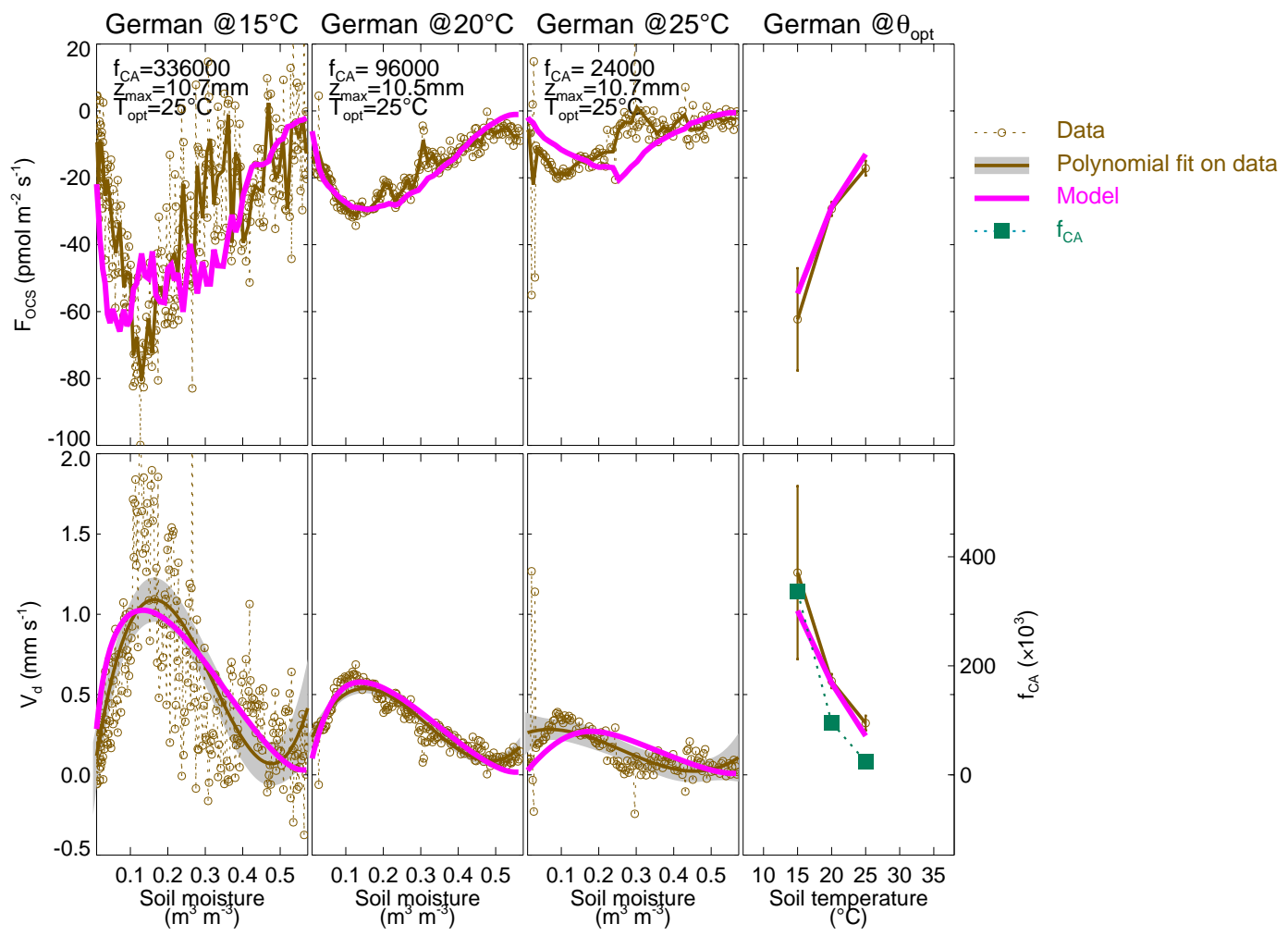

Figure 9. Observed and modelled soil-air OCS flux $\left(F_{\mathrm{OCS}}\right)$ and deposition velocity $\left(V_{\mathrm{d}}\right)$ during soil drying at different incubation temperatures (indicated above each panel) and their value at a soil moisture content $W_{\mathrm{opt}}=0.12 \mathrm{~m}^{3} \mathrm{~m}^{-3}$ (far right panels). The soil moisture and temperature response curves shown here were recalculated from data by Van Diest and Kesselmeier (2008) (open circles and brown line) or computed with our model (thick pink line) using the diffusivity model of Moldrup et al. (2003). For each incubation temperature, a different set of model parameters $\left(f_{\mathrm{CA}}, z_{\max }, T_{\mathrm{opt}}\right)$ was used as indicated in each panel. The data shown here are representative of an agricultural soil near Mainz in Germany (soil weight is $200 \mathrm{~g}$ ).

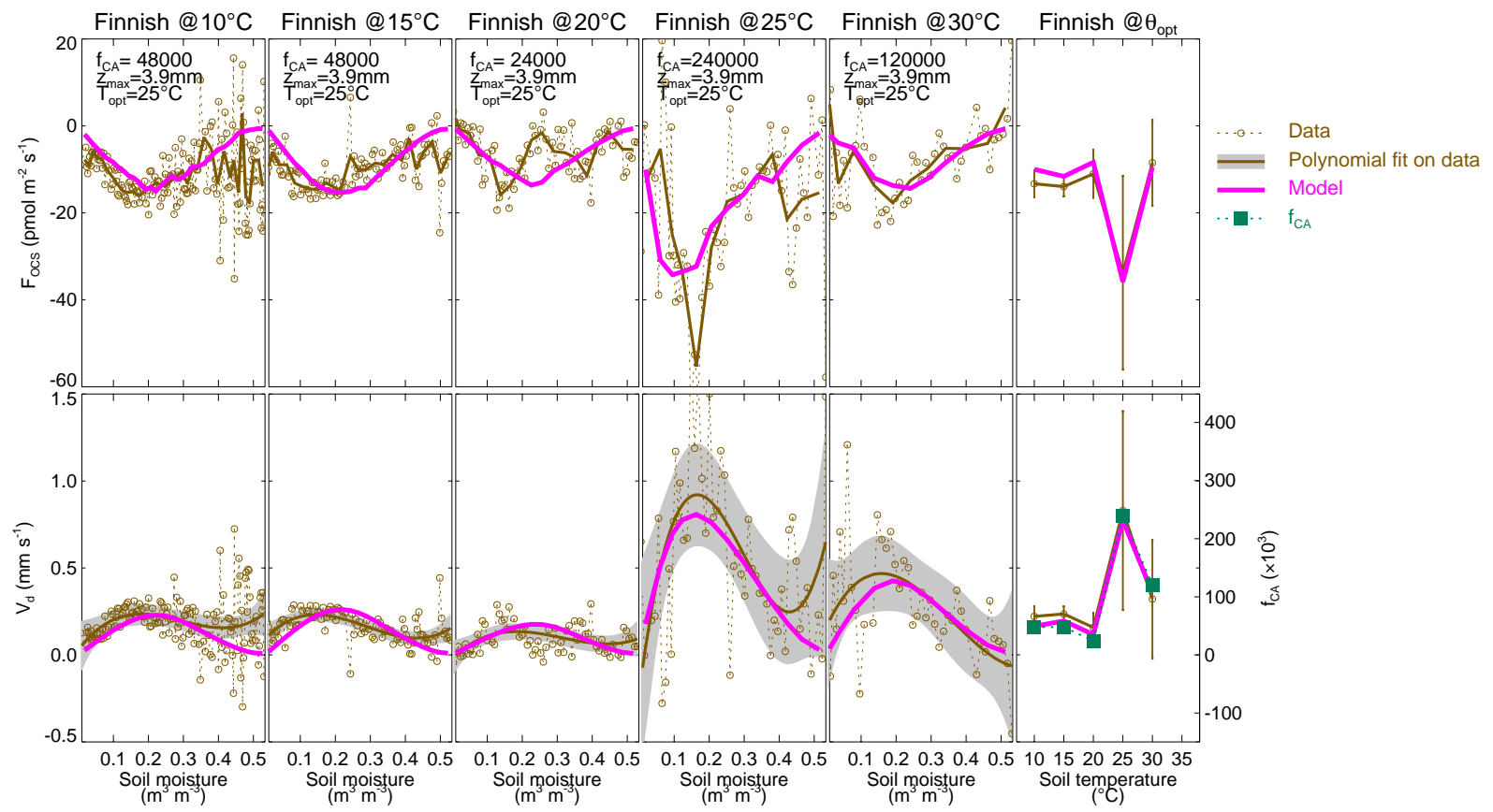

Figure 10. Same as Fig. 9 but for an agricultural soil near Hyytiala in Finland (soil weight is $80 \mathrm{~g}$ ). 


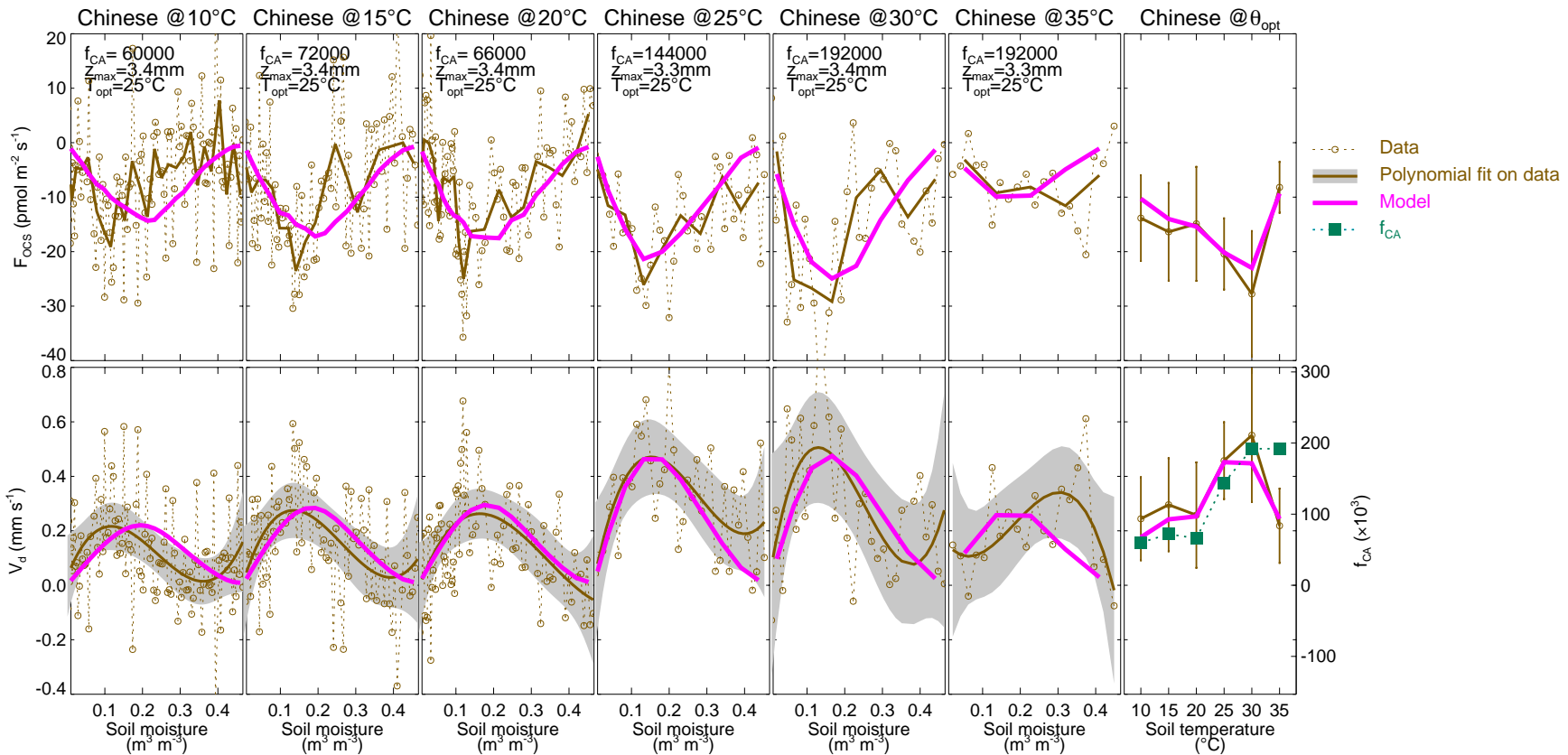

Figure 11. Same as Fig. 9 but for an agricultural soil from north-eastern China (soil weight is $80 \mathrm{~g}$ ).

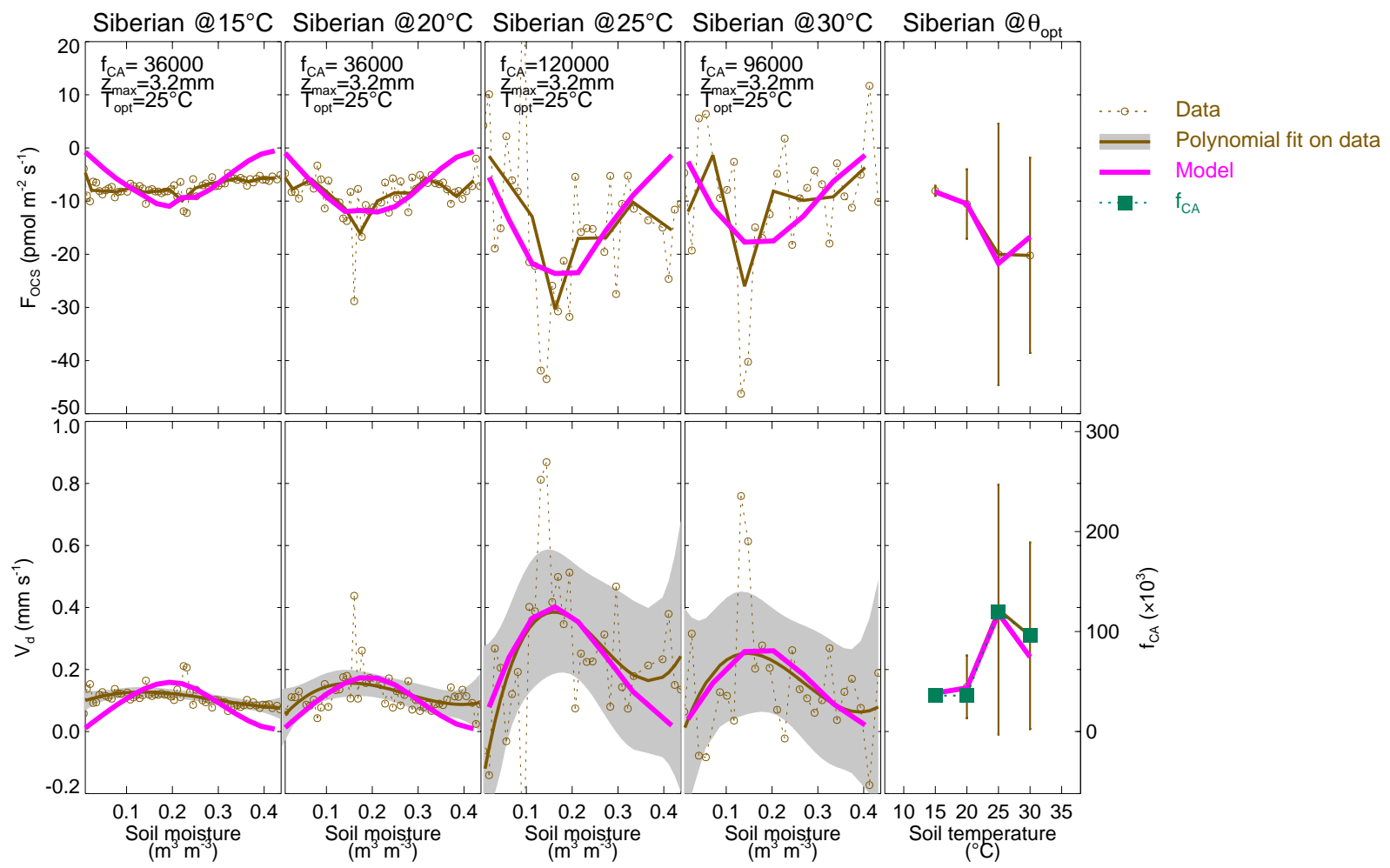

Figure 12. Same as Fig. 9 but for an agricultural soil from Siberia (soil weight is $80 \mathrm{~g}$ ). 
the $V_{\mathrm{d}}$ response to soil drying at a set temperature and for this, they saturated a soil sample with water and acclimated it to a given temperature (between 5 and $35^{\circ} \mathrm{C}$ ), they then recorded the OCS exchange immediately and continued to measure until the soil was completely dry, which usually lasted one to two days. The same soil sample, or a different one from the same geographical location, was then rewatered and reacclimated to a different temperature and another cycle of measurements started. Sometimes several months separated measurements at two different temperatures but storage time (at $5{ }^{\circ} \mathrm{C}$ ) did not seem to affect the soil CA activity (measurements on the same soil and incubation temperature were reproducible). On the other hand incubation temperature clearly differ and, at least for the German soil, samples were not all collected in the same season. This means that, for a given soil origin, the microbial community was experiencing different environmental conditions and history between each drying curve. Thus, the size and diversity of the microbial population were likely different for each incubation temperature, thus justifying the use of different enhancement factors at each temperature. Interestingly $f_{\mathrm{CA}}$ tends to increase with incubation temperature, as we would expect for the microbial biomass. Only the German soil has a higher $f_{\mathrm{CA}}$ at low temperature $\left(15^{\circ} \mathrm{C}\right)$ and this corresponds to a soil sampled at a different period (March) than the other two incubation temperatures (June).

Following this argument it seems that the optimum temperatures observed by Van Diest and Kesselmeier (2008) for different soil types are not a good proxy for the optimal temperature of CA activity $\left(T_{\mathrm{opt}, \mathrm{CA}}\right)$. Using our model we already showed that the optimum temperature for $V_{\mathrm{d}}\left(T_{\mathrm{opt}, V_{\mathrm{d}}}\right)$ was different from $T_{\text {opt,CA }}$, at least for deep soils (Fig. 4). A closer inspection of the results shown in Figs. 9-12 also show that the adjusted $f_{\mathrm{CA}}$ values closely follow the patterns of the maximum $V_{\mathrm{d}}$ at $\theta_{\text {opt }}$ (see right panels in Figs. 9-12). This means that the optimum temperature observed by Van Diest and Kesselmeier (2008) is a better indicator of maximum $f_{\mathrm{CA}}$ or equivalently maximum CA concentration (assuming all the CAs in the soil have similar $k_{\text {cat }} / K_{\mathrm{M}}$ as the pea extracts measured by Protoschill-Krebs et al. (1996)). This could explain why the optimum for the German soil was so low (around $15^{\circ} \mathrm{C}$ ), i.e. lower than expected for $T_{\mathrm{opt}, \mathrm{CA}}$. The presence of a competing enzymatic process, such as OCS emission, could have explained this low $T_{\mathrm{opt}}, V_{\mathrm{d}}$ value (Fig. 7) but it is more likely that the soil sample studied at $15^{\circ} \mathrm{C}$ contained more CA than those used for other incubation temperatures. Measurements on microbial biomass could have helped confirm this hypothesis but were unfortunately not made.

Because $f_{\mathrm{CA}}$ is a fitting parameter in our model, it is important to see if the values that we derived for the different soils are realistic. There are two ways to do so. First, we have a relatively good idea of how much $\mathrm{CA}$ is needed inside the cytosol of leaf mesophyll cells or in unicellular algae, which is of the order of $100 \mu \mathrm{M}$ (Tholen and Zhu, 2011). Assum- ing this CA concentration value is also applicable to microbial cells and using estimates of the soil microbial population size, we can convert this physiological CA concentration $\left([\mathrm{CA}]_{\text {in }}\right)$ into a $\mathrm{CA}$ concentration in the soil matrix ([CA]): $[\mathrm{CA}] \theta=[\mathrm{CA}]_{\text {in }} \rho_{\text {mic }}$, where $\rho_{\text {mic }}\left(\mathrm{m}^{3}\right.$ microbes $\mathrm{m}^{-3}$ soil $)$ denotes the volumetric microbial content of the soil. Using a typical microbial population size of $3 \times 10^{9} \mathrm{~cm}^{-3}$ and an average cell size of $1 \mu^{3}$ (Wingate et al., 2009), we obtain a microbial content of $\rho_{\text {mic }}=0.003 \mathrm{~m}^{3} \mathrm{~m}^{-3}$ and a soil CA content of about $1000 \mathrm{nM}$ (we used $\theta=0.3$ ). Using this value of [CA] and the $k_{\mathrm{cat}} / K_{\mathrm{M}}$ value for OCS $\left(2.39 \mathrm{~s}^{-1} \mu \mathrm{M}^{-1}\right.$ at $20^{\circ} \mathrm{C}$ and $\mathrm{pH}_{\text {in }}$ 8.2) this leads to an $f_{\mathrm{CA}}$ value of about 127000 for OCS, which is in the same order of magnitude as those found for the different soils in this study (between 21600 and 336000, with a median value at 66000). From this crude calculation we can conclude that our $f_{\mathrm{CA}}$ estimates are physiologically meaningful.

Another way of checking if our $f_{\mathrm{CA}}$ estimates are meaningful is to convert them into $f_{\mathrm{CA}}$ equivalents for soil $\mathrm{CO}_{2}$ isotope fluxes, for which we have a better idea of what the expected values should be (Seibt et al., 2006; Wingate et al., $2008,2009,2010)$. The $k_{\text {cat }} / K_{\mathrm{M}}$ value for $\mathrm{CO}_{2}$ in pea extracts has been measured for a $\mathrm{pH}$ range of $6-9$ and at $25^{\circ} \mathrm{C}$ (Bjorkbacka et al., 1999). The $\mathrm{pH}$ response described a similar pattern as the one found for Arabidopsis by Rowlett et al. (2002) (Fig. 2) with a $\mathrm{pK}_{\mathrm{a}}$ of 7.1. Using $x_{\mathrm{CA}}(T)$ and $y_{\mathrm{CA}}$ $\left(\mathrm{pH}_{\mathrm{in}}\right)$ to convert those values to $\mathrm{pH}_{\text {in }} 8.2$ and $20^{\circ} \mathrm{C}$, we obtain a $k_{\text {cat }} / K_{\mathrm{M}}$ value for $\mathrm{CO}_{2}$ of $50 \mathrm{~s}^{-1} \mu \mathrm{M}^{-1}$, i.e. about 20 times greater than the $k_{\text {cat }} / K_{\mathrm{M}}$ for OCS. Given the difference in uncatalysed hydration rates between the two gas species (12000 $\mathrm{s}^{-1}$ for $\mathrm{CO}_{2}$ and $21.5 \mu \mathrm{s}^{-1}$ for OCS at $25^{\circ} \mathrm{C}$ and $\mathrm{pH}=4.5$ ) this means that at equal soil $\mathrm{CA}$ concentration, the $f_{\mathrm{CA}}$ for $\mathrm{CO}_{2}$ should be about 30 times smaller than that derived for OCS. This corresponds to a median $f_{\mathrm{CA}}$ value of 2200 for $\mathrm{CO}_{2}$, i.e. at the higher end of values observed in different soils (Wingate et al., 2009).

The calculation above considers only $\beta$-CA kinetic parameters to relate the soil $\mathrm{CA}$ enhancement factor for OCS to the $f_{\mathrm{CA}}$ for $\mathrm{CO}_{2}$. However other enzymes can catalyse OCS hydrolysis and not have a strong affinity to $\mathrm{CO}_{2}$. For example Smeulders et al. found a carbon disulfide hydrolase from an acido-thermophilic archaeon that was very efficient at catalysing OCS hydrolysis but did not have $\mathrm{CO}_{2}$ as one of its substrates (Smeulders et al., 2012). More recently, Ogawa et al. (2013) found in Thiobacillus thioparus, a sulfur-oxidising bacterium widely distributed in soils and freshwaters, an enzyme that shared a high similarity with $\beta$ CAs and was able to catalyse OCS hydrolysis with a similar efficiency $\left(K_{\mathrm{M}}=60 \mu \mathrm{M}, k_{\text {cat }}=58 \mathrm{~s}^{-1}\right.$ at $\mathrm{pH} 8.5$ and $\left.30^{\circ} \mathrm{C}\right)$ but whose $\mathrm{CO}_{2}$ hydration activity was 3-4 orders of magnitude smaller than that of $\beta$-CAs. For this reason they called this enzyme carbonyl sulfide hydrolase (COSase). The carbon disulfide hydrolase identified by Smeulders et al. (2012) may only be present in extremely acidic environments such as volcanic solfataras, but the COSase found in T. thioparus 
may be more ubiquitous in soils. If this was the case this would imply that the $f_{\mathrm{CA}}$ ratio of $\mathrm{OCS}$ to $\mathrm{CO}_{2}$ is not unique and could, in some soils, be higher than the same ratio derived from $\beta$-CA kinetic parameters only. This could partly explain the highest $f_{\mathrm{CA}}$ values obtained here for OCS.

Higher than expected values of $f_{\mathrm{CA}}$ could also be explained by the fact that we neglected dispersion fluxes when we compared the model against observations. Indeed dispersion fluxes would enhance OCS diffusion (Eq. 15) and result in larger deposition velocities (Eq. 16b) for the same level of CA concentration. Results from Maier et al. (2012) show that the diffusivity $D$ could be easily doubled by the presence of turbulence above the soil surface, which would be equivalent to a doubling of $k$ ( $D$ and $k$ appear as a product in the sink term of Eq. 16b). This means that if dispersion occurred in the experiments (a possibility that we cannot rule out), the $f_{\mathrm{CA}}$ values that we derived from them may be overestimated by a factor of two, bringing them closer to values compatible with $\mathrm{CO}_{2}$ studies.

To conclude, the $f_{\mathrm{CA}}$ values derived here for OCS seem compatible with physiological CA contents and also compatible with $f_{\mathrm{CA}}$ values reported in $\mathrm{CO}_{2}$ isotope studies, given possible affinity differences of some CAs towards OCS and $\mathrm{CO}_{2}$ and possible artefacts of mechanical dispersion caused by fans in some laboratory experiments.

\subsection{Can we transpose laboratory data to field conditions?}

Response curves of OCS deposition rates to soil moisture and temperature have been derived from laboratory experiments similar to those presented here (Kesselmeier et al., 1999) and the derived equations have been used to estimate the OCS uptake by soils at the global scale (Kettle et al., 2002). In addition Van Diest and Kesselmeier have proposed that the optimum (gravimetric) soil moisture content for OCS deposition was around $0.12 \mathrm{~g} \mathrm{~g}^{-1}$, independently of soil type (Van Diest and Kesselmeier, 2008). Our model allows us to verify if such simplification or extrapolation is justified, on a theoretical point of view at least. For semi-infinite soil columns we showed that $\theta_{\text {opt }}$ varied with soil porosity from $0.23 \varphi$ to $0.5 \varphi$, depending on the soil diffusivity model used. Assuming soil bulk density is $2.66(1-\varphi)$, this leads to gravimetric soil moisture contents of between $0.61 \varphi(1-\varphi)$ and $1.33 \varphi(1-\varphi)$, which is clearly dependent on soil type. Also from Fig. 4 we can see that the general shape of the soil moisture response and $\theta_{\text {opt }}$ strongly depend on the exact soil depth used during the experiment, at least for soil less than $3 \mathrm{~cm}$ thick (or more if the CA activity is lower). For thicker soils the deepest soil layers do not contribute to the exchange and we reach the saturation point with soil weight shown in Fig. 5. However in both aforementioned studies (Kesselmeier et al., 1999; Van Diest and Kesselmeier, 2008), care was taken not to reach the saturation point (using soil weights of about $80 \mathrm{~g}$ ). From our model results we can see that this would lead to an overesti- mation of $\theta_{\text {opt }}$ and an overall underestimation of $V_{\mathrm{d}}$ (Fig. 4). Thus based on this observation we would recommend to use soil depths of at least $5-6 \mathrm{~cm}$ in future studies so that the results can be more readily extrapolated to field conditions.

Another difficulty when we want to extrapolate laboratory data to the natural environment is that soil disturbance prior to the experiment (sieving, repacking ...) strongly modifies the gas diffusivity properties of the soil. Our results show that OCS deposition rates can be extremely sensitive to the choice of the diffusivity model used (Fig. 3). In highly compacted, highly aggregated soils the gas diffusivity response to soil moisture content can even become bimodal (Deepagoda et al., 2011), which would certainly have a strong impact on the $V_{\mathrm{d}}-\theta$ relationship. Even without such a complication, our results suggest that deposition rate measurements on repacked soils may not be representative of field conditions because the soil treatment would modify the diffusivity properties of the soil and alter the soil moisture response of the OCS deposition rate. On the other hand, our model (Eq. 17, for semiinfinite soil column) with a soil diffusivity formulation for undisturbed soils (i.e. Mol03u or Deepa11, see Table 1) could be used for interpreting field measurements.

\section{Perspectives}

Our model so far has been tested under steady-state conditions and with fairly uniform soil properties (temperature, moisture, $\mathrm{pH}$...). In the natural environment such conditions are the exception rather than the rule. The model has not been tested either on true temperature response curves as happens in nature with strong diurnal variations of temperature at nearly constant soil moisture content. Indeed data from Van Diest and Kesselmeier (2008) have been collected at constant incubation temperatures and are therefore more indicative of the range of $f_{\mathrm{CA}}$ and $V_{\mathrm{d}}$ values one would expect over a growing season for a given soil type. Surprisingly we could not find published laboratory measurements of $V_{\mathrm{d}}$ where soil temperature was varied diurnally.

Another point that should be addressed in future studies is the characterisation of the soil microbial community size and structure, which should be done systematically with the soil OCS deposition measurements. This would allow us to test whether our upscaling of CA activity to the soil level (Eq. 11a) is correct or not and compatible with physiologically realistic CA contents in soil microbes. Our results so far suggest that the CA contents that we derive seem physiologically meaningful and also compatible with $\mathrm{CO}_{2}$ isotope studies, given the uncertainties in the $k_{\mathrm{cat}} / K_{\mathrm{M}}$ values of different CAs for the two substrates and in the diffusivity model formulation for different experimental setup (see above). Concurrent microbial data on the soil samples could have greatly constrained our downscaling exercise and lead to a more precise picture of possible mismatch between our model and the observations. When combined with both OCS 
and $\mathrm{CO}_{2}$ isotope gas exchange measurements, it could also help identify the microbial communities that are more prone to express specific CAs which favour OCS uptake such as the COSase found in T. thioparus.

Finally our study mostly focused on the temperature response of the OCS production term, but there is a growing body of evidence that other environmental variables trigger OCS production from soils, independently of temperature. In oxic soils, light-induced OCS emissions have been observed (Whelan and Rhew, 2015) whereas in anoxic soils, redox potential seems to be the main trigger (Devai and Delaune, 1995). The mechanisms leading to these OCS emission rates should be better understood before we can incorporate them into a modelling framework and estimate OCS fluxes at large scales. For this reason we strongly suggest systematically reporting measurements of light and soil redox potential (and/or S speciation) in future soil OCS flux studies. 


\section{Appendix A}

Here we derive an equation for the catalysed OCS sink term $\left(S_{\text {cat }}\right)$ that accounts for the co-limitation between the enzymatic reaction that takes place inside microorganisms (at $\mathrm{pH}_{\mathrm{in}}$ and with an OCS concentration $C_{\text {in }}$ ) and the OCS diffusion through the cell wall of the microbes. In this situation, Eq. (9) needs to be rewritten:

$S_{\text {cat }}=\theta k_{\mathrm{cat}}[\mathrm{CA}] \frac{B C_{\mathrm{in}}}{K_{\mathrm{m}}+B C_{\mathrm{in}}} \approx \frac{k_{\mathrm{cat}}}{K_{\mathrm{m}}}[\mathrm{CA}] B \theta C_{\mathrm{in}}$.

The OCS uptake can also be written in terms of transport across the cell wall and the plasma membrane of the microbial cell (see for example Tholen and Zhu (2011):

$S_{\mathrm{cat}}=G_{\mathrm{wall}} V_{\mathrm{mol}}\left(C-C_{\text {in }}\right) S_{\mathrm{wall}}$,

where $G_{\text {wall }}$ ( $\operatorname{mol}\left(\right.$ air) $\mathrm{m}^{-2}$ wall s${ }^{-1}$ ) is the cell wall and plasma membrane aggregated conductance to OCS, $V_{\text {mol }}$ $\left.\left(\mathrm{m}^{3} \text { air mol(air }\right)^{-1}\right)$ is the molar volume of air and $S_{\text {wall }}$ $\left(\mathrm{m}^{2}\right.$ wall $\mathrm{m}^{-3}$ soil) is the microbial cell wall surface density in the soil. Combining Eqs. (A1)-(A2) we can eliminate $C_{\text {in }}$ and express $S$ as a function of $C$ only:

$S_{\text {cat }}=\frac{B \theta k_{\mathrm{cat}}[\mathrm{CA}]}{K_{\mathrm{m}}+B \theta k_{\mathrm{cat}}[\mathrm{CA}] r_{\mathrm{wall}}} C$,

where we defined $1 / r_{\text {wall }}=G_{\text {wall }} V_{\text {mol }} S_{\text {wall }}$. Equation (A3) simplifies to Eq. (9) under the following condition:

$B \theta k_{\text {cat }}[\mathrm{CA}] r_{\text {wall }} \ll K_{\mathrm{m}}$.
Accounting for the dilution of $\mathrm{CA}$ in soils, i.e. $[\mathrm{CA}] \theta=[\mathrm{CA}]_{\text {in }} \rho_{\text {mic }}$, where $\rho_{\text {mic }} \quad\left(\mathrm{m}^{3}\right.$ microbes $\mathrm{m}^{-3}$ soil $)$ is the volumetric density of the soil microbes (that can be expressed as $n_{\text {mic }} V_{0}$ in which $n_{\text {mic }}$ is the number of microbes per soil volume and $V_{0}$ the volume of a single microbial cell), Eq. (A4) can be written as follows:

$\frac{B k_{\mathrm{cat}}[\mathrm{CA}]_{\text {in }}}{G_{\text {wall }} V_{\mathrm{mol}}} \frac{V_{0}}{S_{\text {wallo }}} \ll K_{\mathrm{m}}$,

where $S_{\text {wallo }}$ is the single cell wall surface area. If the microbes are spherical with diameter $D_{0}$, we have $V_{0} / S_{\text {wall }}=D_{0} / 6$. With typical values of $D_{0}=1 \mu \mathrm{m}$, $B=0.5 \mathrm{~m}^{3} \mathrm{~m}^{-3}, V_{\mathrm{mol}}=0.025 \mathrm{~m}^{3} \mathrm{~mol}^{-1}, k_{\mathrm{cat}}=93 \mathrm{~s}^{-1}$ and $G_{\text {wall }}=0.14 \mathrm{~mol} \mathrm{~m}^{-2} \mathrm{~s}^{-1}$ (i.e. $0.35 \mathrm{~cm} \mathrm{~s}^{-1}$, see the note under Table 2 in Evans et al., 2009), the left-hand side of Eq. (A5) equals $0.22 \mu \mathrm{M}$, which is much smaller than $K_{\mathrm{m}}$ (39 $\mu \mathrm{M}$ at $20^{\circ} \mathrm{C}$, (Protoschill-Krebs et al., 1996). In this situation the transport of OCS through the membrane is not a colimiting factor to the OCS uptake (for $\mathrm{CO}_{2}$ it is less true because the left-hand side of Eq. (A5) is around $0.57 \mathrm{mM}$ for a $K_{\mathrm{m}}$ around $3 \mathrm{mM}$ ). Note also that CA is not spread in the entire cell volume so that the cell volume appearing in Eq. (A5) should be somewhat smaller. Although there are large uncertainties on the value of cytoplasmic CA concentration or $k_{\text {cat }} / K_{\mathrm{M}}$, our derivation indicates that these parameters would need to be much higher (by two orders of magnitude) to justify the need to account for the transport of OCS into the cell during microbial consumption. In this study we assumed Eq. (9) to be valid, bearing in mind that the CA concentration we derived from it remains sensitive to the $k_{\text {cat }} / K_{\mathrm{M}}$ value we use. 
Acknowledgements. This work was funded by the European Research Council (ERC starting grant SOLCA), the French national research agency (ANR project ORCA) and the Institut National de la Recherche Agronomique (INRA PhD grant to Joana Sauze). We would like to thank three anonymous reviewers for their constructive comments on an earlier version of this manuscript.

Edited by: X. Wang

\section{References}

Beer, C., Reichstein, M., Tomelleri, E., Ciais, P., Jung, M., Carvalhais, N., Rödenbeck, C., Arain, M. A., Baldocchi, D., Bonan, G. B., Bondeau, A., Cescatti, A., Lasslop, G., Lindroth, A., Lomas, M., Luyssaert, S., Margolis, H., Oleson, K. W., Roupsard, O., Veenendaal, E., Viovy, N., Williams, C., Woodward, F. I., and Papale, D.: Terrestrial Gross Carbon Dioxide Uptake: Global Distribution and Covariation with Climate, Science, 329, 834-838, doi:10.1126/science.1184984, 2010.

Berry, J. A., Wolf, A., Campbell, J. E., Baker, I., Blake, N., Blake, D., Denning, A. S., Kawa, S. R., Montzka, S. A., Seibt, U., Stimler, K., Yakir, D., and Zhu, Z.: A coupled model of the global cycles of carbonyl sulfide and $\mathrm{CO}_{2}$ : A possible new window on the carbon cycle, J. Geophys. Res.-Biogeo., 118, 842-852, doi:10.1002/jgrg.20068, 2013.

Bird, R. B., Stewart, W. E., and Lightfoot, E. N.: Transport phenomena, John Wiley \& Sons, New York, 2002.

Bjorkbacka, H., Johansson, I.-M., and Forsman, C.: Possible Roles for His 208 in the Active-Site Region of Chloroplast Carbonic Anhydrase from Pisum sativum, Arch. Biochem. Biophys., 361, 17-24, 1999.

Blezinger, S., Wilhelm, C., and Kesselmeier, J.: Enzymatic consumption of carbonyl sulfide (COS) by marine algae, Biogeochemistry, 48, 185-197, 2000.

Bremner, J. M. and Banwart, W. L.: Sorption of sulfur gases by soils, Soil Biol. Biochem., 8, 79-83, 1976.

Burnell, J. N. and Hatch, M. D.: Low bundle sheath carbonic anhydrase is apparently essential for effective $\mathrm{C}_{4}$ pathway operation, Plant Physiol., 86, 1252-1256, 1988.

Campbell, J. E., Carmichael, G. R., Chai, T., Mena-Carrasco, M., Tang, Y., Blake, D. R., Blake, N. J., Vay, S. A., Collatz, G. J., Baker, I., Berry, J. A., Montzka, S. A., Sweeney, C., Schnoor, J. L., and Stanier, C. O.: Photosynthetic Control of Atmospheric Carbonyl Sulfide During the Growing Season, Science, 322, 1085-1088, doi:10.1126/science.1164015, 2008.

Castro, M. S. and Galloway, J. N.: A comparison of sulfur-free and ambient air enclosure techniques for measuring the exchange of reduced sulfur gases between soils and the atmosphere, J. Geophys. Res.-Atmos., 96, 15427-15437, 1991.

Choi, J.-G., Do, D. D., and Do, H. D.: Surface Diffusion of Adsorbed Molecules in Porous Media: Monolayer, Multilayer, and Capillary Condensation Regimes, Ind. Eng. Chem. Res., 40, 4005-4031, doi:10.1021/ie010195z, 2001.

De Bruyn, W. J., Swartz, E., Hu, J. H., Shorter, J. A., Davidovits, P., Worsnop, D. R., Zahniser, M. S., and Kolb, C. E.: Henry's law solubilities and Śetchenow coefficients for biogenic reduced sulfur species obtained from gas-liquid uptake measurements, J. Geophys. Res.-Atmos., 100, 7245-7251, 1995.
Deepagoda, T. K. K. C., Moldrup, P., Schjønning, P., Wollesen de Jonge, L., Kawamoto, K., and Komatsu, T.: Density-Corrected Models for Gas Diffusivity and Air Permeability in Unsaturated Soil, Vadose Zone J., 10, 226-238, doi:10.2136/vzj2009.0137, 2011.

Delaune, R. D. and Reddy, K. R.: Redox Potential, in: Encyclopedia of Soils in the Environment, edited by: Hillel, D., 366-371, 2005.

Devai, I. and Delaune, R. D.: Formation of volatile sulfur compounds in salt marsh sediment as influenced by soil redox condition, Org. Geochem., 23, 283-287, 1995.

Elliott, S., Lu, E., and Rowland, F. S.: Rates and mechanisms for the hydrolysis of carbonyl sulfide in natural waters, Environ. Sci. Technol., 23, 458-461, doi:10.1021/es00181a011, 1989.

Evans, J. R., Kaldenhoff, R., Genty, B., and Terashima, I.: Resistances along the $\mathrm{CO}_{2}$ diffusion pathway inside leaves, J. Exp. Bot., 60, 2235-2248, doi:10.1093/jxb/erp117, 2009.

Falta, R. W., Javandel, I., Pruess, K., and Witherspoon, P. A.: Density-Driven Flow of Gas in the Unsaturated Zone Due to the Evaporation of Volatile Organic-Compounds, Water Resour. Res., 25, 2159-2169, 1989.

Frankenberg, C., Fisher, J. B., Worden, J., Badgley, G., Saatchi, S. S., Lee, J.-E., Toon, G. C., Butz, A., Jung, M., Kuze, A., and Yokota, T.: New global observations of the terrestrial carbon cycle from GOSAT: Patterns of plant fluorescence with gross primary productivity, Geophys. Res. Lett., 38, L17706, doi:10.1029/2011GL048738, 2011.

Friedlingstein, P., Bopp, L., Rayner, P., Cox, P. M., Betts, R., Jones, C., Bloh, Von, W., Brovkin, V., Cadule, P., and Doney, S. C.: Climate-carbon cycle feedback analysis: Results from the C4MIP model intercomparison, J. Climate, 19, 3337-3353, 2006.

Gurney, K. R. and Eckels, W. J.: Regional trends in terrestrial carbon exchange and their seasonal signatures, Tellus B, 63, 328339, doi:10.1111/j.1600-0889.2011.00534.x, 2011.

Haritos, V. S. and Dojchinov, G.: Carbonic anhydrase metabolism is a key factor in the toxicity of $\mathrm{CO}_{2}$ and $\mathrm{COS}$ but not $\mathrm{CS}_{2}$ toward the flour beetle Tribolium castaneum [Coleoptera: Tenebrionidae], Comp. Biochem. Phys. C, 140, 139-147, doi:10.1016/j.cca.2005.01.012, 2005.

Husson, O.: Redox potential (Eh) and $\mathrm{pH}$ as drivers of soil/plant/microorganism systems: a transdisciplinary overview pointing to integrative opportunities for agronomy, Plant Soil, 362, 389-417, doi:10.1007/s11104-012-1429-7, 2012.

Isik, S., Kockar, F., Aydin, M., Arslan, O., Guler, O. O., Innocenti, A., Scozzafava, A., and Supuran, C. T.: Carbonic anhydrase inhibitors: inhibition of the beta-class enzyme from the yeast Saccharomyces cervevisiae with sulfonamides and sulfamates, Bioorgan. Med. Chem., 17, 1158-1163, doi:10.1016/j.bmc.2008.12.035, 2009.

Kesselmeier, J., Teusch, N., and Kuhn, U.: Controlling variables for the uptake of atmospheric carbonyl sulfide by soil, J. Geophys. Res, 104, 11577-11584, 1999.

Kettle, A. J., Kuhn, U., Hobe, von, M., Kesselmeier, J., and Andreae, M. O.: Global budget of atmospheric carbonyl sulfide: Temporal and spatial variations of the dominant sources and sinks, J. Geophys. Res, 107, 4658, doi:10.1029/2002JD002187, 2002. 
Krulwich, T. A., Sachs, G., and Padan, E.: Molecular aspects of bacterial $\mathrm{pH}$ sensing and homeostasis, Nat. Rev. Microbiol., 9, 330-343, doi:10.1038/nrmicro2549, 2011.

Kuhn, U., Ammann, C., Wolf, A., Meixner, F., Andreae, M., and Kesselmeier, J.: Carbonyl sulfide exchange on an ecosystem scale: soil represents a dominant sink for atmospheric COS, Atmos. Environ., 33, 995-1008, 1999.

Launois, T., Peylin, P., Belviso, S., and Poulter, B.: A new model of the global biogeochemical cycle of carbonyl sulfide - Part 2: Use of carbonyl sulfide to constrain gross primary productivity in current vegetation models, Atmos. Chem. Phys., 15, 9285-9312, doi:10.5194/acp-15-9285-2015, 2015.

Liu, J., Geng, C., Mu, Y., Zhang, Y., Xu, Z., and Wu, H.: Exchange of carbonyl sulfide (COS) between the atmosphere and various soils in China, Biogeosciences, 7, 753-762, doi:10.5194/bg-7753-2010, 2010.

Liu, Y., He, H., and Ma, Q.: Temperature Dependence of the Heterogeneous Reaction of Carbonyl Sulfide on Magnesium Oxide, J. Phys. Chem. A, 112, 2820-2826, doi:10.1021/jp711302r, 2008.

Liu, Y., Ma, Q., and He, H.: Comparative study of the effect of water on the heterogeneous reactions of carbonyl sulfide on the surface of $\alpha-\mathrm{Al}_{2} \mathrm{O}_{3}$ and $\mathrm{MgO}$, Atmos. Chem. Phys., 9, 62736286, doi:10.5194/acp-9-6273-2009, 2009.

Liu, Y., Ma, J., and He, H.: Heterogeneous reactions of carbonyl sulfide on mineral oxides: mechanism and kinetics study, Atmos. Chem. Phys., 10, http://www.atmos-chem-phys.net/10/10335/ 2010/acp-10-10335-2010-supplement.pdf, 2010a.

Liu, Y., Ma, J., Liu, C., and He, H.: Heterogeneous uptake of carbonyl sulfide onto kaolinite within a temperature range of 220-330 K, J. Geophys. Res, 115, D24311, doi:10.1029/2010JD014778, 2010b.

Maier, M., Schack-Kirchner, H., Aubinet, M., Goffin, S., Longdoz, B., and Parent, F.: Turbulence Effect on Gas Transport in Three Contrasting Forest Soils, Soil Sci. Soc. Am. J., 76, 1518, doi:10.2136/sssaj2011.0376, 2012.

Manzoni, S. and Katul, G. G.: Invariant soil water potential at zero microbial respiration explained by hydrological discontinuity in dry soils, Geophys. Res. Lett., 41, 7151-7158, doi:10.1002/2014GL061467, 2014.

Maseyk, K., Berry, J. A., Billesbach, D., Campbell, J. E., Torn, M. S., Zahniser, M., and Seibt, U.: Sources and sinks of carbonyl sulfide in an agricultural field in the Southern Great Plains, P. Natl. Acad. Sci. USA, 111, 9064-9069, doi:10.1073/pnas.1319132111, 2014.

Massman, W. J., Sommerfeld, R. A., Mosier, A. R., Zeller, K. F., Hehn, T. J., and Rochelle, S. G.: A model investigation of turbulence-driven pressure-pumping effects on the rate of diffusion of $\mathrm{CO}_{2}, \mathrm{~N}_{2} \mathrm{O}$, and $\mathrm{CH}_{4}$ through layered snowpacks, J. Geophys. Res.-Atmos., 102, 18851-18863, 1997.

Massman, W. J.: A review of the molecular diffusivities of $\mathrm{H}_{2} \mathrm{O}$, $\mathrm{CO}_{2}, \mathrm{CH}_{4}, \mathrm{CO}, \mathrm{O}_{3}, \mathrm{SO}_{2}, \mathrm{NH}_{3}, \mathrm{~N}_{2} \mathrm{O}, \mathrm{NO}$, and $\mathrm{NO}_{2}$ in air, $\mathrm{O}_{2}$ and $\mathrm{N}_{2}$ near STP, Atmos. Environ., 32, 1111-1127, 1998.

Mello, W. Z. and Hines, M. E.: Application of static and dynamic enclosures for determining dimethyl sulfide and carbonyl sulfide exchange in Sphagnum peatlands: Implications for the magnitude and direction of flux, J. Geophys. Res, 99, 14-601-14-607, 1994.

Merlin, C., Masters, M., McAteer, S., and Coulson, A.: Why Is Carbonic Anhydrase Essential to Escherichia coli?, J. Bacteriol., 185, 6415-6424, doi:10.1128/JB.185.21.6415-6424.2003, 2003.
Millington, R. J. and Quirk, J. P.: Permeability of porous solids, T. Faraday Soc., 57, 1200-1207, 1961.

Moldrup, P., Olesen, T., Komatsu, T., Yoshikawa, S., Schjønning, P., and Rolston, D. E.: Modeling diffusion and reaction in soils: $\mathrm{X}$. A unifying model for solute and gas diffusivity in unsaturated soil, Soil Sci., 168, 321-337, doi:10.1097/00010694200305000-00002, 2003.

Montzka, S. A., Calvert, P., Hall, B. D., Elkins, J. W., Conway, T. J., Tans, P. P., and Sweeney, C.: On the global distribution, seasonality, and budget of atmospheric carbonyl sulfide (COS) and some similarities to $\mathrm{CO}_{2}$, J. Geophys. Res, 112, D09302, doi:10.1029/2006JD007665, 2007.

Ogawa, T., Noguchi, K., Saito, M., Nagahata, Y., Kato, H., Ohtaki, A., Nakayama, H., Dohmae, N., Matsushita, Y., Odaka, M., Yohda, M., Nyunoya, H., and Katayama, Y.: Carbonyl Sulfide Hydrolase from Thiobacillus thioparus Strain THI115 Is One of the $\beta$-Carbonic Anhydrase Family Enzymes, J. Am. Chem. Soc., 135, 3818-3825, doi:10.1021/ja307735e, 2013.

Olesen, T., Gamst, J., Moldrup, P., Komatsu, T., and Rolston, D.: Diffusion of sorbing organic chemicals in the liquid and gaseous phases of repacked soil, Soil Sci. Soc. Am. J., 65, 1585-1593, 2001.

Penman, H.: Gas and vapour movements in the soil: I. The diffusion of vapours through porous solids, J. Agr. Sci., 30, 437-462, 1940.

Petersen, L. W., Moldrup, P., Elpharan, Y. H., Jacobsen, O. H., Yamaguchi, T., and Rolston, D. E.: The Effect of Moisture and Soil Texture on the Adsorption of Organic Vapors, J. Environ. Qual., 24, 752-759, 1995.

Piao, S., Sitch, S., Ciais, P., Friedlingstein, P., Peylin, P., Wang, X., Ahlström, A., Anav, A., Canadell, J. G., Cong, N., Huntingford, C., Jung, M., Levis, S., Levy, P. E., Li, J., Lin, X., Lomas, M. R., Lu, M., Luo, Y., Ma, Y., Myneni, R. B., Poulter, B., Sun, Z., Wang, T., Viovy, N., Zaehle, S., and Zeng, N.: Evaluation of terrestrial carbon cycle models for their response to climate variability and to $\mathrm{CO}_{2}$ trends, Glob. Change Biol., 19, 2117-2132, doi:10.1111/gcb.12187, 2013.

Protoschill-Krebs, G. and Kesselmeier, J.: Enzymatic pathways for the consumption of carbonyl sulphide (COS) by higher plants, Bot. Acta, 105, 206-212, 1992.

Protoschill-Krebs, G., Wilhelm, C., and Kesselmeier, J.: Consumption of Carbonyl Sulphide by Chlamydomonas reinhardtii with Different Activities of Carbonic Anhydrase (CA) Induced by Different $\mathrm{CO}_{2}$ Growing Regimes, Bot. Acta, 108, 445-448, 1995.

Protoschill-Krebs, G., Wilhelm, C., and Kesselmeier, J.: Consumption of carbonyl sulphide (COS) by higher plant carbonic anhydrase (CA), Atmos. Environ., 30, 3151-3156, 1996.

Rowlett, R. S., Tu, C., McKay, M. M., Preiss, J. R., Loomis, R. J., Hicks, K. A., Marchione, R. J., Strong, J. A., Donovan Jr., G. S., and Chamberlin, J. E.: Kinetic characterization of wild-type and proton transfer-impaired variants of $\beta$-carbonic anhydrase from Arabidopsis thaliana, Arch. Biochem. Biophys., 404, 197-209, 2002.

Sandoval-Soto, L., Stanimirov, M., von Hobe, M., Schmitt, V., Valdes, J., Wild, A., and Kesselmeier, J.: Global uptake of carbonyl sulfide (COS) by terrestrial vegetation: Estimates corrected by deposition velocities normalized to the uptake of carbon dioxide $\left(\mathrm{CO}_{2}\right)$, Biogeosciences, 2, 125-132, doi:10.5194/bg-2-1252005, 2005. 
Scanlon, B. R., Nicot, J. P., and Massmann, J. W.: Soil gas movement in unsaturated systems, in: Soil Physics Companion, CRC Press, Boca Raton, FL, 297-341, 2002.

Seibt, U., Wingate, L., Lloyd, J., and Berry, J. A.: Diurnally variable $\delta^{18} \mathrm{O}$ signatures of soil $\mathrm{CO}_{2}$ fluxes indicate carbonic anhydrase activity in a forest soil, J. Geophys. Res, 111, G04005, doi:10.1029/2006JG000177, 2006.

Seibt, U., Kesselmeier, J., Sandoval-Soto, L., Kuhn, U., and Berry, J. A.: A kinetic analysis of leaf uptake of COS and its relation to transpiration, photosynthesis and carbon isotope fractionation, Biogeosciences, 7, 333-341, doi:10.5194/bg-7-333-2010, 2010.

Smeulders, M. J., Barends, T. R. M., Pol, A., Scherer, A., Zandvoort, M. H., Udvarhelyi, A., Khadem, A. F., Menzel, A., Hermans, J., Shoeman, R. L., Wessels, H. J. C. T., van den Heuvel, L. P., Russ, L., Schlichting, I., Jetten, M. S. M., and Op den Camp, H. J. M.: Evolution of a new enzyme for carbon disulphide conversion by an acidothermophilic archaeon, Nature, 478, 412-416, doi:10.1038/nature10464, 2012.

Smith, K., Jakubzick, C., Whittam, T., and Ferry, J.: Carbonic anhydrase is an ancient enzyme widespread in prokaryotes, P. Natl. Acad. Sci. USA, 96, 15184-15189, 1999.

Steinbacher, M., Bingemer, H., and Schmidt, U.: Measurements of the exchange of carbonyl sulfide (OCS) and carbon disulfide $\left(\mathrm{CS}_{2}\right)$ between soil and atmosphere in a spruce forest in central Germany, Atmos. Environ., 38, 6043-6052, doi:10.1016/j.atmosenv.2004.06.022, 2004.

Stimler, K., Montzka, S. A., Berry, J. A., Rudich, Y., and Yakir, D.: Relationships between carbonyl sulfide (COS) and $\mathrm{CO}_{2}$ during leaf gas exchange, New Phytol., 186, 869-878, doi:10.1111/j.1469-8137.2010.03218.x, 2010.

Stimler, K., Berry, J. A., and Yakir, D.: Effects of Carbonyl Sulfide and Carbonic Anhydrase on Stomatal Conductance, Plant Physiol., 158, 524-530, doi:10.1104/pp.111.185926, 2012.

Sun, W., Maseyk, K., Lett, C., and Seibt, U.: A soil diffusionreaction model for surface COS flux: COSSM v1, Geosci. Model Dev., 8, 3055-3070, doi:10.5194/gmd-8-3055-2015, 2015.

Syrjänen, L., Vermelho, A. B., de Almeida Rodrigues, I., CorteReal, S., Salonen, T., Pan, P., Vullo, D., Parkkila, S., Capasso, C., and Supuran, C. T.: Cloning, Characterization, and Inhibition Studies of a $\beta$-Carbonic Anhydrase from Leishmania donovani chagasi, the Protozoan Parasite Responsible for Leishmaniasis, J. Med. Chem., 56, 7372-7381, doi:10.1021/jm400939k, 2013.

Tholen, D. and Zhu, X.-G.: The Mechanistic Basis of Internal Conductance: A Theoretical Analysis of Mesophyll Cell Photosynthesis and $\mathrm{CO}_{2}$ Diffusion, Plant Physiol., 156, 90-105, doi:10.1104/pp.111.172346, 2011

Ulshöfer, V. S., Flock, O. R., Uher, G., and Andreae, M. O.: Photochemical production and air-sea exchange of carbonyl sulfide in the eastern Mediterranean Sea, Mar. Chem., 53, 25-39, 1996.

van Bochove, E., Beauchemin, S., and Thériault, G.: Continuous multiple measurement of soil redox potential using platinum microelectrodes, Soil Sci. Soc. Am. J., 66, 1813-1820, 2002.

Van Diest, H. and Kesselmeier, J.: Soil atmosphere exchange of carbonyl sulfide (COS) regulated by diffusivity depending on waterfilled pore space, Biogeosciences, 5, 475-483, doi:10.5194/bg-5475-2008, 2008.
Welp, L. R., Keeling, R. F., Meijer, H. A. J., Bollenbacher, A. F., Piper, S. C., Yoshimura, K., Francey, R. J., Allison, C. E., and Wahlen, M.: Interannual variability in the oxygen isotopes of atmospheric $\mathrm{CO}_{2}$ driven by El Niño, Nature, 477, 579-582, doi:10.1038/nature10421, 2011.

Whelan, M. E. and Rhew, R. C.: Carbonyl sulfide produced by abiotic thermal and photodegradation of soil organic matter from wheat field substrate, J. Geophys. Res.-Biogeo., 120, 54-62, doi:10.1002/2014JG002661, 2015.

Whelan, M. E., Min, D.-H., and Rhew, R. C.: Salt marsh vegetation as a carbonyl sulfide (COS) source to the atmosphere, Atmos. Environ., 73, 131-137, doi:10.1016/j.atmosenv.2013.02.048, 2013.

White, M. L., Zhou, Y., Russo, R. S., Mao, H., Talbot, R., Varner, R. K., and Sive, B. C.: Carbonyl sulfide exchange in a temperate loblolly pine forest grown under ambient and elevated $\mathrm{CO}_{2}$, Atmos. Chem. Phys., 10, 547-561, doi:10.5194/acp-10-547-2010, 2010.

Wilhelm, E., Battino, R., and Wilcock, R. J.: Low-pressure solubility of gases in liquid water, Chem. Rev., 77, 219-262, 1977.

Wingate, L., Seibt, U., Maseyk, K., Ogée, J., Almeida, P., Yakir, D., Pereira, J. S., and Mencuccini, M.: Evaporation and carbonic anhydrase activity recorded in oxygen isotope signatures of net $\mathrm{CO}_{2}$ fluxes from a Mediterranean soil, Glob. Change Biol., 14, 2178-2193, doi:10.1111/j.1365-2486.2008.01635.x, 2008.

Wingate, L., Ogée, J., Cuntz, M., Genty, B., Reiter, I., Seibt, U., Yakir, D., Maseyk, K., Pendall, E. G., Barbour, M. M., Mortazavi, B., Burlett, R., Peylin, P., Miller, J., Mencuccini, M., Shim, J. H., Hunt, J., and Grace, J.: The impact of soil microorganisms on the global budget of delta- ${ }^{18} \mathrm{O}$ in atmospheric $\mathrm{CO}_{2}$, P. Natl. Acad. Sci. USA, 106, 22411-22415, doi:10.1073/pnas.0905210106, 2009.

Wingate, L., Ogée, J., Burlett, R., and Bosc, A.: Strong seasonal disequilibrium measured between the oxygen isotope signals of leaf and soil $\mathrm{CO}_{2}$ exchange, Glob. Change Biol., 16, 3048-3064, doi:10.1111/j.1365-2486.2010.02186.x, 2010.

Wohlfahrt, G., Brilli, F., Hörtnagl, L., Xu, X., Bingemer, H., Hansel, A., and Loreto, F.: Carbonyl sulfide (COS) as a tracer for canopy photosynthesis, transpiration and stomatal conductance: potential and limitations, Plant Cell Environ., 35, 657667, doi:10.1111/j.1365-3040.2011.02451.x, 2011.

Yamaguchi, T., Poulsen, T., Moldrup, P., and Fukushima, T.: Predictive model for adsorption of volatile organic chemicals on soils, Environmental Engineering Research, 36, 477-482, 1999.

Yi, Z., Wang, X., Sheng, G., Zhang, D., Zhou, G., and Fu, J.: Soil uptake of carbonyl sulfide in subtropical forests with different successional stages in south China, J. Geophys. Res, 112, D08302, doi:10.1029/2006JD008048, 2007.

Yi, Z., Wang, X., Sheng, G., and Fu, J.: Exchange of carbonyl sulfide (OCS) and dimethyl sulfide (DMS) between rice paddy fields and the atmosphere in subtropical China, Agr. Ecosyst. Environ., 123, 116-124, doi:10.1016/j.agee.2007.05.011, 2008.

Zeebe, R. E.: On the molecular diffusion coefficients of dissolved $\mathrm{CO}_{2}, \mathrm{HCO}_{3}^{-}$and $\mathrm{CO}_{3}^{2-}$ and their dependence on isotopic mass, Geochim. Cosmochim. Ac., 75, 2483-2498, doi:10.1016/j.gca.2011.02.010, 2011. 